\title{
Development of a vibration free machine structure for high-speed micro-milling center
}

\author{
Arnab Das \\ Indian Institute of Technology (ISM) Dhanbad \\ Shashank Shukla \\ Indian Institute of Technology (ISM) Dhanbad \\ Mohan Kumar \\ Indian Institute of Technology (ISM) Dhanbad \\ Chitransh Singh \\ Indian Institute of Technology (ISM) Dhanbad \\ Madan Lal Chandravanshi \\ Indian Institute of Technology (ISM) Dhanbad \\ Vivek Bajpai ( $\nabla$ vbajpai007@rediffmail.com ) \\ Indian Institute of Technology (ISM) Dhanbad https://orcid.org/0000-0003-4811-6611
}

\section{Research Article}

Keywords: High-speed micro-milling, Machine structure, Modal analysis, Frequency response analysis, Dynamic stability

Posted Date: March 15th, 2021

DOl: https://doi.org/10.21203/rs.3.rs-314125/v1

License: (c) (i) This work is licensed under a Creative Commons Attribution 4.0 International License. Read Full License

Version of Record: A version of this preprint was published at The International Journal of Advanced Manufacturing Technology on July 21st, 2021. See the published version at https://doi.org/10.1007/s00170-021-07533-1. 


\title{
Development of a vibration free machine structure for high-speed micro-milling center
}

\author{
Arnab Das • Shashank Shukla • Mohan \\ Kumar - Chitransh Singh - Madan Lal \\ Chandravanshi * Vivek Bajpai *
}

Received: date / Accepted: date

\begin{abstract}
The demand of ultra-precision micro-machine tools is growing day by day due to exigent requirements of miniaturized components. High accuracy, good dimensional precision and smooth surface finish are the major characteristics of these ultra-precision machine tools. High-speed machining has been adopted to increase the productivity using high-speed spindles. However, machine tool vibration is a major issue in high-speed machining. Vibration significantly deteriorates the quality of micro-machining in terms of dimensional precision and surface finish. This paper describes a design methodology of a closed type machine structure for vibration minimization of a high-speed micro-milling center. The rigid machine structure has provided plenty of stiffness and the damping capability to the machine tool without utilizing vibration absorbers. The models of the machine structures have been generated and assembled in AutoCAD 3D. The performances of the integrated micro-milling machine tools were determined by finite element analysis. The best model has been selected and proposed for manufacturing. Additionally, simulation results were validated by comparing with experimental results. Eventually, after manufacturing and assembly, experiments have been performed and determined that the amplitude of vibration was approaching towards nanometer level throughout the working range of the high-speed spindle. The machine tool was capable to fabricate miniaturized components with fine surface finish.
\end{abstract}

Keywords High-speed micro-milling · Machine structure · Modal analysis · Frequency response analysis · Dynamic stability

\footnotetext{
Department of Mechanical Engineering Indian Institute of Technology (ISM) Dhanbad Jharkhand, 826004, India

* Corresponding author

E-mail: vivek@iitism.ac.in
} 


\section{Introduction}

Micro-machining technologies have versatile applications in several industries like electro-optics, automotive, biotechnology, aerospace, information technology etc to fabricate high accuracy miniaturized components. The growing demand of micro-machining technology has facilitated the requirement of highperformance and efficient ultra-precision machines tools [1]. Highly precise complex 3D shapes with mirror finish on different materials can be fabricated in those ultra-precision machine tools in a expeditious and cost-effective way $[2,3]$. Micro-milling is an adaptable technology for generating miniaturized components with complex geometric features and mirror finish on difficult-tomachine materials $[4,5]$, even on silicon [6]. The major limitation of the micro machining is low tool stiffness and low MRR. High speed micro-machining has been adopted to improve MRR and reduce the chip load. The mechanism of chip formation and the grade of surface finish have made high-speed micromilling a distinctive one from other traditional material removal processes [7]. The static and dynamic performances of the high-speed micro-machine tools have directly influenced the machining performances. However, determination of the dynamic performances of those high-speed machine tools is a challenging issue by creating real prototype [8]. Finite element analysis has been adopted as a comprehensive mean for that issue [9].

High-speed micro-milling machine tools have required high speed spindles to maintain the machining speed and efficiency. But at high spindle speeds, acute vibration takes place in the machine tools [10]. This jeopardizes the dimensional accuracy; precision and surface finish of micro size products. Apart from this, chatter may be developed due to vibration and that can lead to tool wear and breakage of the cutting tool [11]. Chatter may also affect the spindle and the machine tool [12]. Therefore, vibration isolation is necessary to maintain the accuracy and surface finish of the machined surface and also to maintain the tool life. The stiffness of the machine structure plays a very crucial role for machining efficiency and vibration isolation of a machine tool [13]. Hence, the high-speed micro-milling machine structure must have good static, dynamic stiffness and damping performance for quality machining performance [1].

Several approaches have been reported for development of the ultra-precision machine tools since 1980's [14]. However, micro machining has been incorporated with ultra-precision precision machining since last two decades. Luo et al. [15] developed a bench-top UPM machine tool which was capable to machine miniaturized components with high accuracy. The accuracy of the spindle and stages including the damping quality of the machine structure has significant influence on the machining accuracy in that machine tool. Huo et al. $[9,16]$ proposed a design approach of high-speed ultra-precision micro-milling machine tool. They concluded that closed type machine structure has shown higher stiffness and damping capability as compared to open type machine structure. However, medium to high frequency vibration still exists within the range of high-speed spindle. Park et al. [17] proposed a design methodology of a 
meso-scale machine tool based on analytical and finite element modeling. They focused on optimization of the structure in order to achieve higher stiffness. They have found that the vibration was increased and the stiffness was reduced with the increase in height of the column. The stiffness of the machine structure has been considered as a crucial factor influencing the product quality in terms of dimensional precision and surface finish [13]. Liang et al [18] designed an ultra-precision diamond fly-cutting machine tool. For improvement in accuracy of that ultra-precision machine, they focused on minimizing the size of machine components to reduce the cantilever action and thus, decrement in deformation due to vibration. They also suggested closed type structure for better rigidity. Therefore, the most considerable factor during development of a high-speed precision machine tool is minimization of machine tool vibration which creates a major area for future research.

For structural vibration minimization, Yang et al. [19] developed a vibration isolator mechanism based on quasi zero stiffness which significantly reduced the vibration transmissibility. Therefore, it has worked as an effective mean of low frequency vibration. Additionally, Zhang et al. [20] applied an active vibration control method using nonlinear vibration absorber which resulted in lower resonant amplitude of vibration. Semm et al. [21] incorporated substructure coupling approach considering local and global damping to improve the accuracy of FEM simulation in order to determine damping performance of a machine tool. Zhang et al. [22] proposed a discrete time-delay chatter control method with closed loop chatter stability model for milling process. It stabilized the machining parameters and reduced the amplitude of chatter vibration by $78.6 \%$. Orra and Chaudhury [23] presented a electro-magnetorheological damping system with a closed loop feedback control system to suppress the machine tool vibration during turning process. The damper has been attached under the tool holder and generated counter force to suppress tool vibration when excited by current signal. Representing the contacts in machine tool is a challenging issue which is required for accurate prediction of machine tool behavior. For ease of computational issues, the contact forces have been directly mapped onto the FE model of machine tool topological optimization problem [24]. Mohammadi and Ahmadi [25] proposed a single degree of freedom model with nonlinear restoring force to determine the vibration response of a KUKA machining robot at tool center point. However, it cannot accurately predict the system dynamics. The design of the machine structure is significant for vibration isolation of the precision micro-machine tool. The machine structure contributes to the machine tool dynamics. The goal of the research was to reduce the vibration of the machine structure so that number of resonances with the working frequency of the machine tool has been reduced. The perfect design of the machine structure possessed very low amplitude of vibration under the resonance condition within the working range.

The current study reveals the development strategy of a gantry type machine structure for a high-speed micro-milling center to minimize the machine tool vibration. The material of the machine structure has been determined 


\section{Model validation}

Figure 1 shows the flow chart of the development strategy. The design methodology is based on FEM analysis, especially modal analysis and frequency response analysis. Therefore, it has been focused primarily to validate the models before starting the design approach.

For validation, a bridge type structure has been fabricated and its CAD model has been replicated in AutoCAD 3D. Modal analysis simulation has been performed on that model in ANSYS and the results were compared with results of experimental modal analysis. The experimental modal analysis has been performed by exciting the bridge structure using an impact hammer and the signals have been collected by roving accelerometer technique. The accelerometers of Bruel \& Kjaer have been used for this purpose. The FRF data was generated by photon+ dynamic signal analyzer and processed in MEScope Ves software to determine the natural frequencies experimentally. The results of experimental modal analysis of the bridge structure have shown a good similarity with the simulation result of modal analysis in ANSYS workbench with a maximum of $11 \%$ deviation which was found in the third mode. Therefore, the model was further expanded to find out the vibration free machine structure. Figure 2 represents the fabricated bridge structure and the compar- 


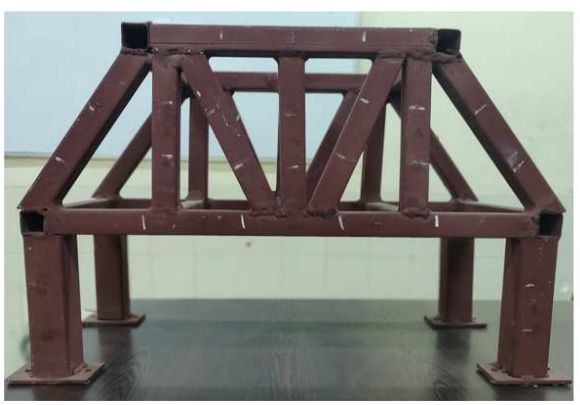

(a)

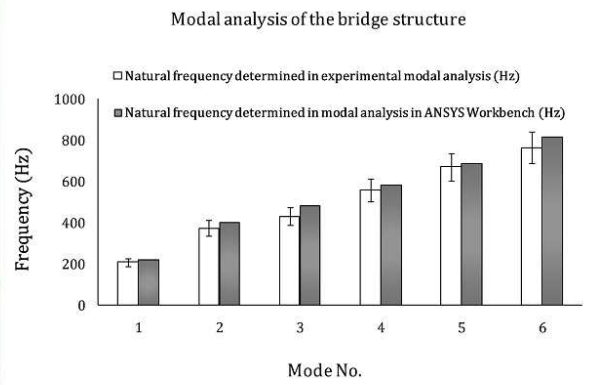

(b)

Fig. 2 (a) The bridge structure used for validation of modal analysis model in ANSYS workbench, (b) the comparison of natural frequencies of the bridge structure found in ANSYS modal analysis and experimental modal analysis

ative study of natural frequencies found in ANSYS and experimental modal analysis.

Initially, after validation of modal analysis, a model of machine structure was developed in AutoCAD for the micro-milling machine and the natural frequencies of the individual structure were determined by modal analysis in ANSYS. The material chosen for the structure was mild steel due to its easy availability. The natural frequency of 1st mode of the individual mild steel frame was $143.38 \mathrm{~Hz}$, found in ANSYS modal analysis. After assembling the linear stages, spindle and spindle holding fixture with the structure, static structural analysis, modal analysis and harmonic response analysis were performed on the CAD model of the assembled machine tool. The static structural analysis over the assembled model of mild steel frame has determined maximum 7 micron deformation under constant static load. However, the natural frequency of the 1st mode of the assembled frame was $59.83 \mathrm{~Hz}$ found in ANSYS modal analysis. The reduction in natural frequency of the assembled frame than the individual one is due to the increase in mass because of the attachment of stages, spindle and spindle holder. The harmonic response analysis over the assembled mild steel frame was performed applying average constant cutting force on the tip of the spindle. The range of frequency was given $150 \mathrm{~Hz}$ to $1000 \mathrm{~Hz}$ according to spindle working frequency. It has determined maximum amplitude of 5.03 micron along $\mathrm{Y}$ axis at a frequency of 235 $\mathrm{Hz}$. The maximum amplitude of vibration along $\mathrm{Z}$ axis was 2.59 micron at a frequency of $490 \mathrm{~Hz}$.

Subsequently, the structure of mild steel was manufactured for the micromilling machine and fixed over a honeycomb table as shown in Fig. 3 (a). Experimental modal analysis was performed over the unassembled machine structure using impact hammer and accelerometers in order to check the similarity with the simulation result. The results of experimental modal analysis have also shown good similarity with the simulation result. Maximum $17 \%$ deviation was found in first mode as shown in Fig. 3 (b). The linear stages and the spindle along with the spindle holding fixture were assembled and at- 
tached to the structure and the honeycomb table. An experimental frequency response analysis was performed to check the amplitude of vibration of that mild steel machine structure using accelerometers under machining condition at constant chip load and varying rotational velocity. The depth of cut was constant in every case and feed rate was being varied with rotational speed to keep chip load as constant. The cutter used was a two flute milling cutter. The FRF generated by photon+ dynamic signal analyzer was taken and processed in MEScope Ves software to determine the amplitudes of vibration at resonance condition. The results of experimental frequency response analysis were compared with the results of harmonic response analysis simulation and the similarity was determined. The experimental frequency response analysis of the steel structure at machining condition shows that maximum deformation along $\mathrm{Y}$ direction is 5.7 micron in resonance with frequency $265 \mathrm{~Hz}$. However, along $\mathrm{Z}$ direction, the maximum deformation is 2.7 micron in resonance with frequency $484 \mathrm{~Hz}$. The plot is almost similar with the plot achieved in harmonic response analysis in ANSYS. A continuous plot can be achieved in ANSYS; however, this is impractical to achieve such continuous plot in experimental frequency response analysis. Therefore, slight variation occurs in these plots. Figure 4 represents the comparative results of frequency response determined in experiment and FEM analysis. Hence the model was validated. It was observed that the amplitude of vibration reduced with increase in rotational speed while machining. This is due to lower force transmission to the structure at higher rotational speed. Above $1000 \mathrm{~Hz}$, no peak was found as the maximum working frequency of the spindle was $1000 \mathrm{~Hz}$. The deformation was measured in these two directions because the maximum deformation was found in $\mathrm{Y}$ and $\mathrm{Z}$ directions in the mode shapes in modal analysis and the deformation along $\mathrm{X}$ direction was negligible.

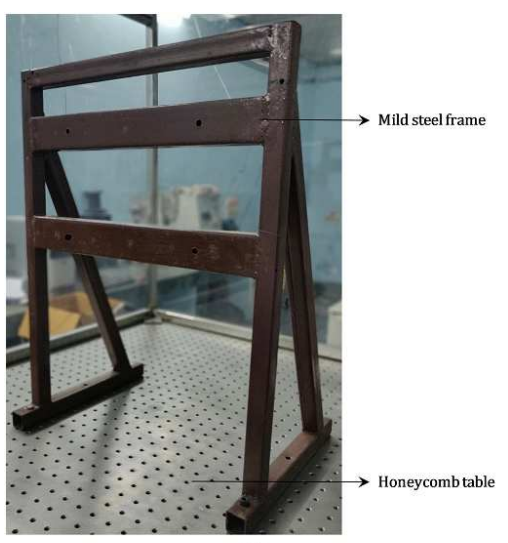

(a)

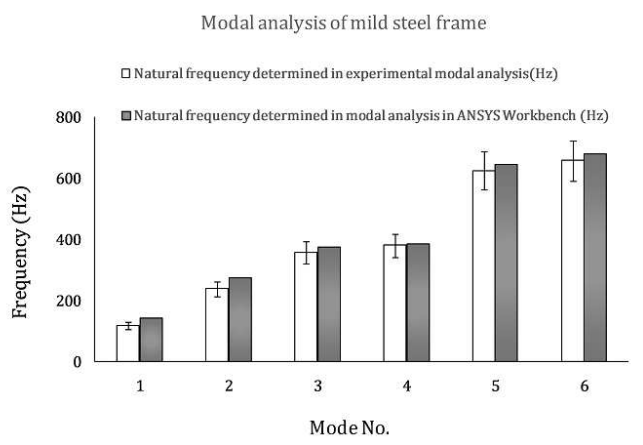

(b)

Fig. 3 (a) The mild steel frame for the micro-milling set up, (b) the comparison of natural frequencies of the mild steel frame determined in ANSYS modal analysis and experiments 


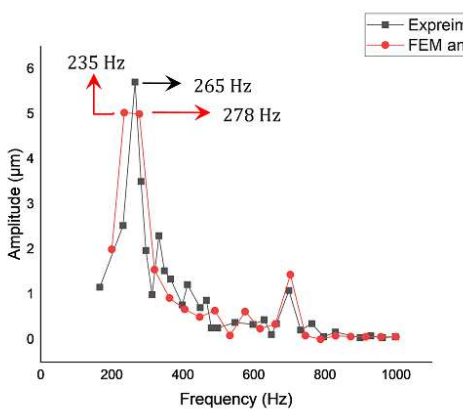

(a) Y axis

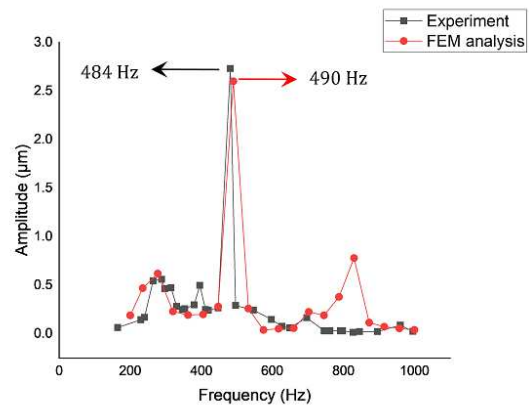

(b) $\mathrm{Z}$ axis

Fig. 4 Comparison of the results of frequency response analysis on the mild steel frame determined in experiments and FEM analysis

\section{Preparation of the model and FEM analysis}

\subsection{Preparation of the model}

The design approach is a trial and error approach that incorporated 3D modeling of the structure components, their assemblies and finally evaluation of their performances by FEM analyses. Based on the results of the analyses, the change of materials, structural configuration and the dimensional optimization have been performed to improve the performances in terms of static, dynamic stiffness and damping capability. Eventually, the best model has been selected as the vibration free structure and proposed for manufacturing. Most of the previous researches have focused on external vibration absorbers in mechanical structures to improve the damping capability [26,27]. However, this research has been focused on the internal damping capability of the structure to reduce the machine tool vibration without utilizing any external vibration absorber. The design of the machine structure of the high speed micro-milling machine has been made closed type as open type structure are more assailable to vibration [9].

\subsubsection{Materials selection}

The initial design criterion involved selection of the material for the machine structure. A material having higher damping capacity, good specific stiffness, and small thermal expansion co-efficient with low specific heat capacity may be considered as good structural material. Additionally, the manufacturability of materials has been considered during design. Therefore, the material selection is the primitive factor in machine tool design. Generally, metallic structures possesses low damping performance due to lower damping capacity [28]. Cast iron has been used for conventional machine structure for higher damping characteristics and load carrying capacity [29]. However, elevated processing cost and poor environmental properties have limited cast iron for 


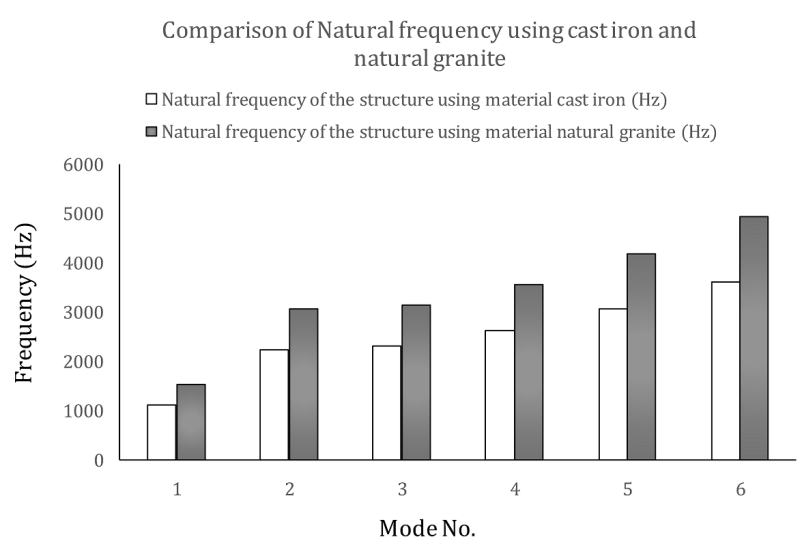

Fig. 5 The comparison of natural frequencies of the proposed machine structure using cast iron and natural granite

precision machine tool structure [30]. Natural granite has shown better performance than cast iron in terms of rigidity, damping quality, thermal stability and dynamic load carrying capacity $[31,32]$. Besides, good form stability and flatness have made natural granite superior for high-speed ultra-precision machine tool structure [33]. For all of those characteristics, both cast iron and natural granite were selected for the machine structure. The performances were evaluated for a single CAD model using both the materials in ANSYS modal analysis. The minimum natural frequency of the structure was 1118.8 $\mathrm{Hz}$ when the material was cast iron. However, the minimum natural frequency was $1528.9 \mathrm{~Hz}$ using natural granite as the material of the machine structure. Also natural granite is capable for higher vibration damping as compared to cast iron. Hence, for better performance, natural granite was selected as the material of the invented machine structure. Figure 5 shows the comparison of natural frequencies of the structure using both cast iron and natural granite.

\subsubsection{Structural configuration}

The parts of the high-speed micro-milling machine were divided into two categories. The machine structure is the stationary part and the other parts such as spindle, linear stages are moving parts. Before starting the design of the machine structure, the moving parts were selected. According to the bearing stiffness, accuracy, damping capacity and thermal performance, a spindle of model AG62-60-0.24-P-DS, manufactured by Fischer spindle was selected. The minimum rotational speed of the spindle is $10000 \mathrm{rpm}$ and maximum rotational speed is $60000 \mathrm{rpm}$. Therefore corresponding minimum and maximum working frequencies of the spindle are $166.6 \mathrm{~Hz}$ and $1000 \mathrm{~Hz}$ respectively. The specifications of the spindle have been described in Tab. 1. The spindle holding fixture was made of mild steel. Further linear stages were selected according to their resolution, accuracy and repeatability. The linear stages of model LMS- 
200-200 were selected for the high-speed micro-milling center. The maximum travel ranges of the stages are $150 \mathrm{~mm}$ and maximum base area is $200 \mathrm{~mm}$ $\times 250 \mathrm{~mm}$. The specifications of the linear stages have been represented in Tab. 2. After the selection of the moving parts, the machine structure was designed for providing the accommodation of these parts and vibration isolation. The whole design approach incorporated a number of 3D models among which the best one has been selected for manufacturing based on static and dynamic stability. This description only involved the best model which has been considered as vibration free.

Table 1 Technical specifications of the high-speed spindle

\begin{tabular}{cccccccc}
\hline $\begin{array}{c}\text { Spindle } \\
\text { speed } \\
(\mathrm{RPM})\end{array}$ & Motor type & $\begin{array}{c}\text { Torque } \\
(\mathrm{N} . \mathrm{m})\end{array}$ & $\begin{array}{c}\text { Motor } \\
\text { power } \\
(\mathrm{kW})\end{array}$ & $\begin{array}{c}\text { Cooling } \\
\text { system }\end{array}$ & $\begin{array}{c}\text { Lubrication } \\
\text { system }\end{array}$ & $\begin{array}{c}\text { Mass } \\
(\mathrm{kg})\end{array}$ & $\begin{array}{c}\text { Tool } \\
\text { change }\end{array}$ \\
\hline $\begin{array}{c}10000- \\
60000\end{array}$ & Asynchronous & 0.24 & 1.5 & Liquid & Grease & 3.3 & Pneumatic \\
\hline
\end{tabular}

Table 2 Technical specifications of the motorized linear stages

\begin{tabular}{ccccccc}
\hline Stages & $\begin{array}{c}\text { Travel } \\
\text { range } \\
(\mathrm{mm})\end{array}$ & $\begin{array}{c}\text { Resolution Accuracy } \\
(\mathrm{nm})\end{array}$ & $\begin{array}{c}\text { Maximum } \\
\text { travel } \\
\text { speed }\end{array}$ & $\begin{array}{c}\text { Minimum } \\
\text { travel } \\
\text { speed } \\
(\mathrm{mm} / \mathrm{min})\end{array}$ & $\begin{array}{c}\text { Load } \\
\text { carrying } \\
\text { capacity } \\
(\mathrm{mg})\end{array}$ \\
\hline X stage & 150 & 312 & \pm 2.5 & 240 & 0.01 & 50 \\
Y stage & 150 & 312 & \pm 2.5 & 240 & 0.01 & 20 \\
Z stage & 150 & 312 & \pm 2.5 & 240 & 0.01 & 50 \\
\hline
\end{tabular}

Machine bed accommodates the overall machine tool. So the stiffness and the load carrying capacity of the machine bed must be high enough. For the machine structure, the length of the machine bed is $660 \mathrm{~mm}$ and the width is $556 \mathrm{~mm}$. The maximum height of the machine bed is $100 \mathrm{~mm}$. Two slots of $50 \mathrm{~mm}$ depth were given at both sides of the bed. The frame columns were attached into the slots of the bed from bottom as well as from transverse side so that the transverse movement of the frame column due to vibration could be restricted. The X-Y linear stages were fixed at the center of the machine bed from the transverse side. The total distance required in $\mathrm{X}$ or $\mathrm{Y}$ direction for the travel of the X-Y linear stages is $350 \mathrm{~mm}$ (200 mm stage width +150 $\mathrm{mm}$ travel). Therefore, the distance provided between two slots is $354 \mathrm{~mm}$ so that the X-Y linear stages can travel without getting obstructed between the frame columns. A through hole of $40 \mathrm{~mm}$ diameter were provided at the machine bed so that the wires connected to the control systems of the spindle and linear stages can be passed through that hole. 
The design of the frame column was generated as per the vibration point of view and the manufacturability of granite. The thickness of the frame column is $100 \mathrm{~mm}$ and its height is $275 \mathrm{~mm}$. The heights of the frame columns were optimized in order to minimize the natural vibration. The thickness was adjusted to provide sufficient stiffness. The frame columns are carrying the load of the upper block. The upper block is a granite block designed for the closed type machine structure. It carries the vertical linear stage along with spindle holding fixture and spindle. The thickness of the upper block is 100 $\mathrm{mm}$ and the maximum height is $207.5 \mathrm{~mm}$. The height of the upper block has been adjusted to minimize the natural vibration of the overall machine structure. After generating each part of the machine structure they were integrated. Figure 6 represents the CAD models of all components of the vibration free high-speed micro-milling machine tool. Figure 7 (a) represents the unassembled vibration free machine structure which has been integrated with spindle and linear stages as shown in Fig. 7 (b).

\subsection{Static structural analysis}

Static structural analysis has calculated the influence of static loading on the machine structure neglecting the effects of vibration. The assembled CAD model of that machine structure has undergone static structural analysis in ANSYS considering the materials of each part and applying constant static load in each $\mathrm{X}, \mathrm{Y}$ and $\mathrm{Z}$ direction at the tip of the tool holder of the spindle. The bottom of the machine bed was remained fixed. Total deformation and von-mises stress have been selected as output parameters. The maximum deformation of 2.85 micron and negligible stress were found in static structural analysis. The deformation variation in the overall machine tool is shown in Fig. 8(a). The variation of von-mises stresses in the high-speed machine tool is depicted in Fig. 8(b). The maximum von-mises stress was 27.5 MPa found in the structure. The effect of the bearings in the spindle was not considered in this analysis. Therefore, the maximum deformation as well as stress was found at the collet of the spindle. It can be seen that the proposed model of machine structure has provided superior rigidity to the assembled highspeed micro-milling machine tool. The maximum deflections in the frames were approaching below $10 \mu \mathrm{m}$ for almost all designs. Therefore, it cannot be determined the best design based on the performance of only static structural analysis.

\subsection{Modal analysis}

After static structural analysis, the natural frequencies of the assembled machine tool models have been determined by modal analysis in ANSYS workbench. This analysis uses Block Lanczos mode extraction method to determine the natural frequencies. The structural configurations which created less number of resonances with the working frequency of the spindle were selected. The 


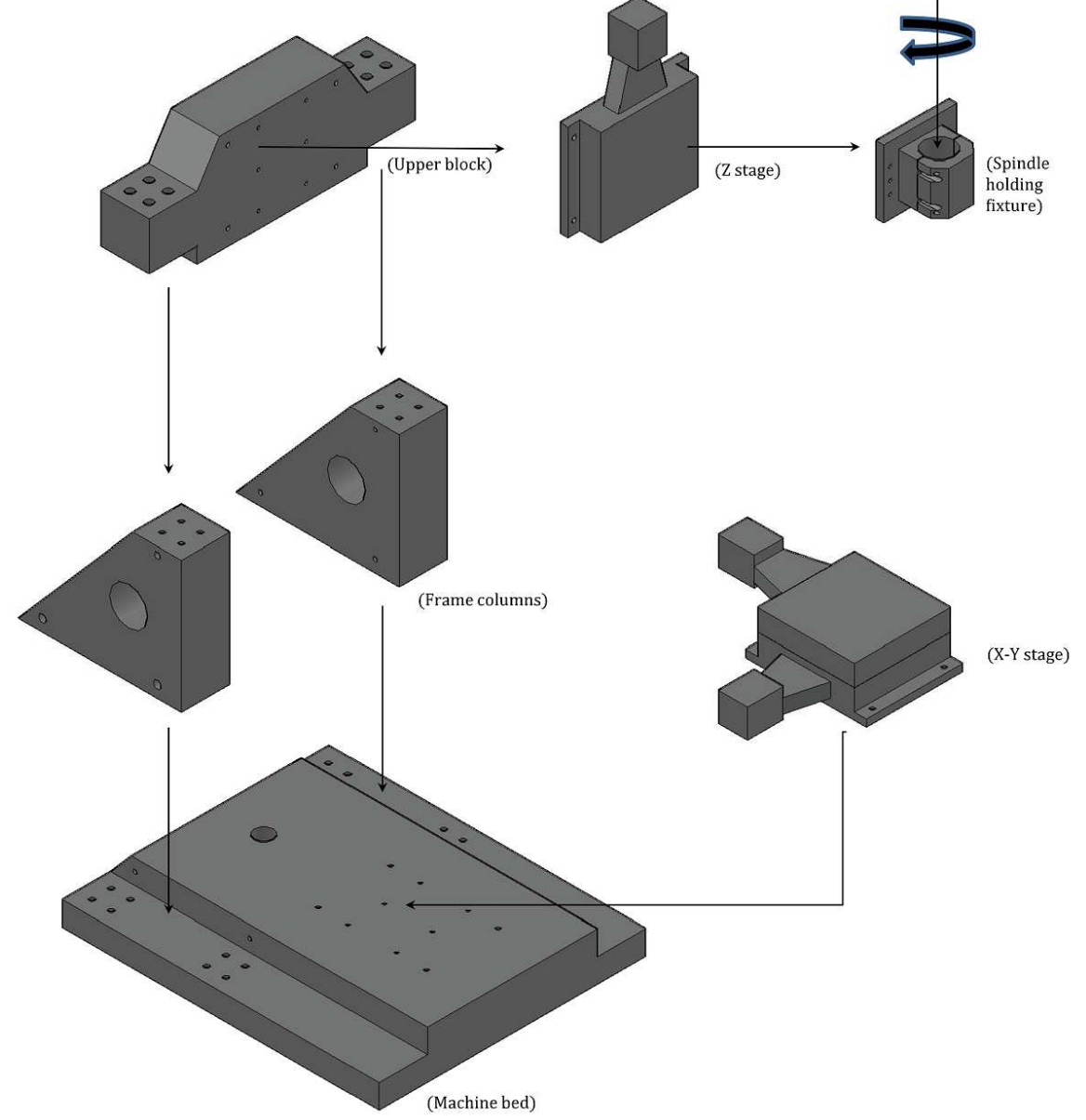

Fig. 6 The components of the vibration free high-speed micro-milling center prepared in AutoCAD

purpose of the modal analysis was to find out the corresponding rotational speeds for resonance. Maximum rotational speed of $60000 \mathrm{rpm}$ has been applied at the spindle collet. The spindle frequency can be depicted from the equation $\mathrm{f}=\mathrm{N} / 60$, where $\mathrm{N}$ and $\mathrm{f}$ represents the rotational speed and corresponding working frequency of the spindle respectively. Therefore, the maximum working frequency of the spindle was $1000 \mathrm{~Hz}$. The natural frequency of 1st mode of the assembled model was $718.79 \mathrm{~Hz}$ determined in modal analysis. It was found that only four natural frequencies are there below or adjacent to 


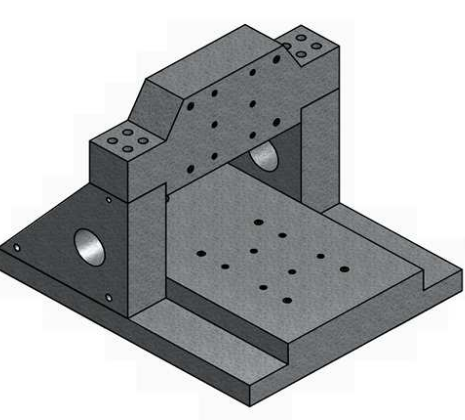

(a) Unassembled machine structure

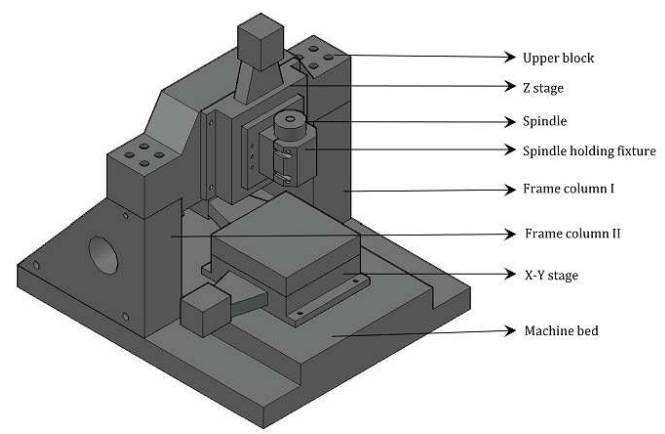

(b) Assembled machine structure

Fig. 7 CAD model of the vibration free machine structure

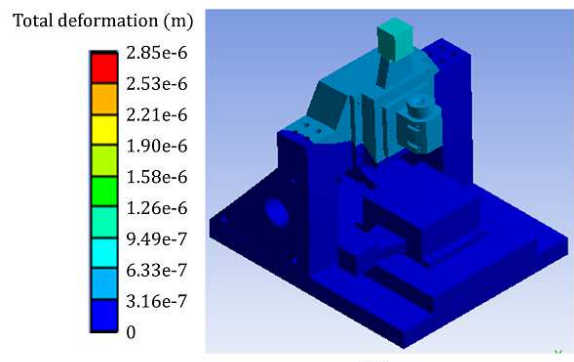

(a)

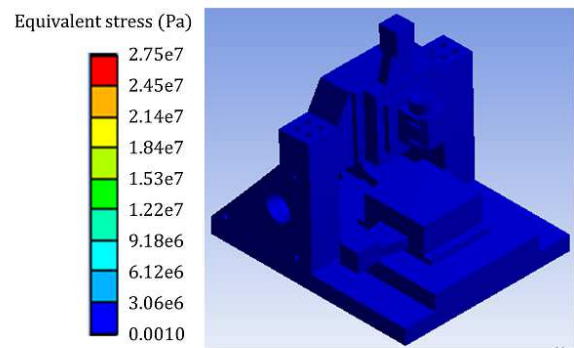

(b)

Fig. 8 The results of static structural analysis of the proposed model determined in ANSYS workbench. (a) Total deformation, and (b) Equivalent stress

$1000 \mathrm{~Hz}$ as shown in Fig. 9. However, in the 2nd and 3rd natural frequencies, deformations were found only in the servo motors of linear stages according to the mode shapes. Therefore, only two natural frequencies are there where the structure may create resonance with the working frequency of the spindle. The first four mode shapes have been represented in Fig. 10.

The materials selections, structural configuration, and dimensional change have taken a major part to determine the mode shapes, natural frequencies, and deformations in different mode shapes under resonance. A $36 \%$ improvement has been observed for a single model, when the material has changed from cast iron to natural granite as shown in Fig. 5. Therefore, the number of resonances has been reduced when the structure material was natural granite. Similarly, a small increase in height of the upper block resulted in significant deformation as shown in the mode shapes, represented in Fig. 11. All of the issues have been taken into consideration during the design of the machine structure.

The proposed model has shown better result compared to other models considering the dimensions and spaces for movement of the stages. It was not much excited with the working frequency of the spindle in terms of creating resonances. However, the resonant frequencies have changed under the action 


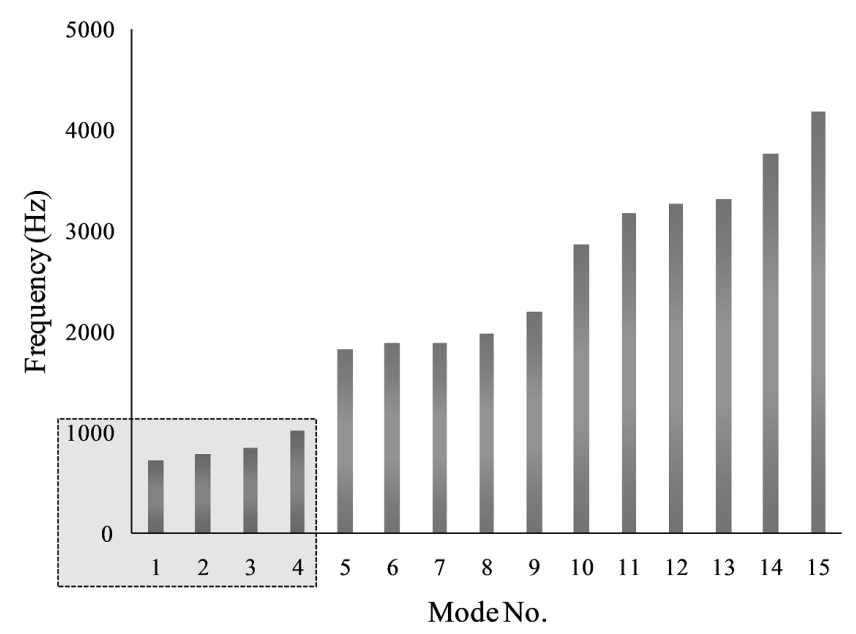

Fig. 9 Plots of first 15 natural frequencies of the proposed assembled machine structure determined in ANSYS modal analysis
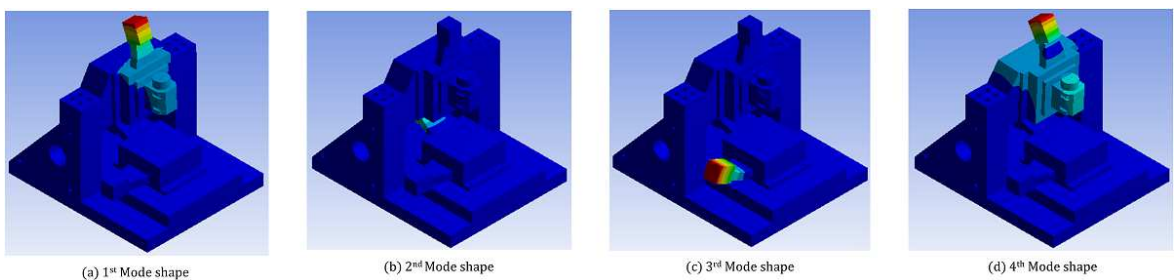

Fig. 10 First four mode shapes of the assembled machine structure, determined in ANSYS modal analysis

of forced vibration occurring due to the action of cutting force. Therefore, the effect of machining operation on the machine structure cannot be considered in modal analysis.

\subsection{Harmonic response analysis}

Harmonic response analysis was performed on the assembled models of the machine tools to check the amplitude of vibration under forced vibration. In this analysis, the machine structure has been excited by a series of harmonic cutting forces $\mathrm{F}$, acting between the milling cutter and the workpiece. The harmonic force $\mathrm{F}$ can be expressed as, $\left[F=F_{0} \sin (\omega t)\right]$; where $\omega$ is the given frequency of the cutting operation [9]. The tip of the tool holder has been given an average cutting force $F_{0}$. The range of frequency was given according to the working cutting frequency i.e. $166 \mathrm{~Hz}$ to $1000 \mathrm{~Hz}$. The model which showed lowest amplitude of vibration under the action of cutting force has been finalized as the optimized structure. Then that machine structure was proposed for man- 


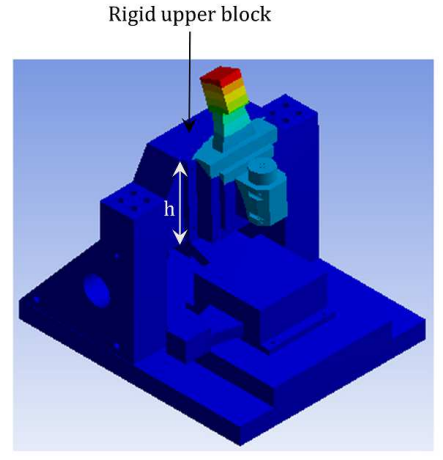

(a) $\mathrm{h}=207.5 \mathrm{~mm}$

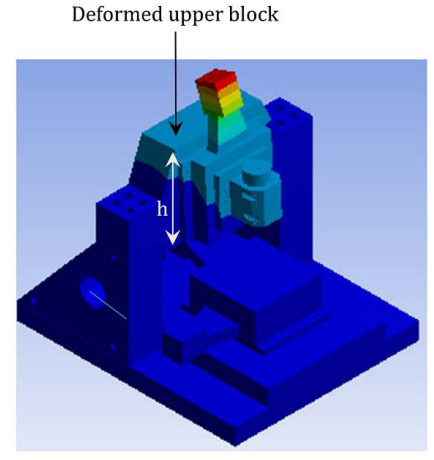

(b) $\mathrm{h}=250 \mathrm{~mm}$

Fig. 11 First mode shapes of the assembled machine structure with different heights of the upper block

ufacturing. It has been observed that the structures made of natural granite possessed higher structural rigidity as compared to other structural materials like cast iron. The amplitude of vibration for the proposed machine structure was approaching towards nanometer level. The maximum amplitude was 0.567 micron along $\mathrm{Y}$ axis and the peak was found in $235 \mathrm{~Hz}$. However, maximum amplitude along $\mathrm{Z}$ axis was 0.108 micron and corresponding frequency was 235 $\mathrm{Hz}$. The frequency response plots of the assembled machine structure along $\mathrm{Y}$ and $\mathrm{Z}$ axes have been represented in Fig. 12. The deformation was measured along these two directions because the maximum deformation was found in $\mathrm{Y}$ and $\mathrm{Z}$ directions in the mode shapes found in modal analysis and the deformation along $\mathrm{X}$ direction was negligible. The analysis result has shown that the amplitude of vibration has been reduced by approximately 10 times for the proposed machine structure as compared to initial mild steel structure. Hence, the structure has provided good rigidity and damping performance to the micro-milling machine tool. It absorbed a huge extent of noise generated by vibration during the machining operation and resisted the displacement of the machine tool. Therefore, the structural damping contributed considerably to reduce the vibration of high-speed micro-milling center.

After evaluating the performance in ANSYS, the model was proposed for manufacturing. The maximum floor area required for the machine structure was $660 \mathrm{~mm} \times 556 \mathrm{~mm}$. The maximum height of the structure was $500 \mathrm{~mm}$. The weight of the complete structure was $200 \mathrm{~kg}$. The attachments with fasteners take a major part for structural damping as slightly loose fastening may results in enormous vibration in the machine structure. It was taken into consideration during manufacturing. 

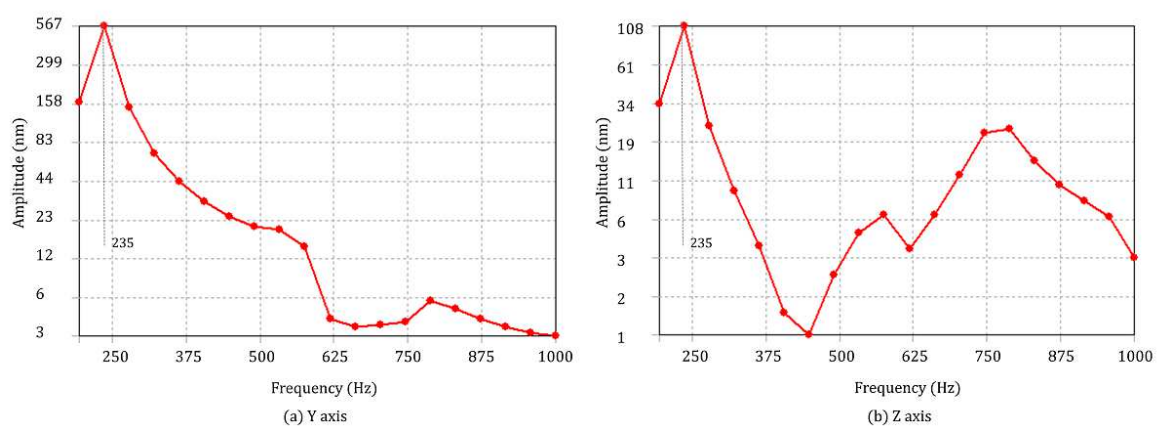

Fig. 12 Plots of harmonic response analysis of the assembled machine tool model determined in ANSYS

\section{Experimental performance of the machine structure}

\subsection{Experimental setup}

After manufacturing, the machine structure has been assembled with the spindle and linear stages. Figure 13 represents the assembled high-speed micromilling center. Experimental frequency response analysis has been performed in the assembled machine tool during machining to check the amplitude of vibration. The machining operations have been performed under dry condition with constant chip load (Chip load $=\frac{f}{N Z}$; where $\mathrm{f}$ is feed rate per min, $\mathrm{N}$ is $\mathrm{rpm}$, and $\mathrm{Z}$ is the number of flutes). The chip load was same as the previous experiment performed in mild steel frame. The range of rotational speed has been varied from 10000 to $60000 \mathrm{rpm}$ with constant intervals. The feed rates have been varied accordingly to maintain constant chip load. Depth of cut was constant for each run. The variations of all machining parameters and the workpiece material were same as the previous experiment in mild steel frame. The vibration data have been collected by accelerometers using Bruel and Kjaer 4 channel dynamic signal analyzer. The recorded signals were processed in MeScope Ves and the amplitudes of vibration were determined in this software. The experiment has been performed with a two flute milling cutter. Furthermore, the machining experiment has been repeated with a four flute milling cutter with same process parameters. These results were compared with the results of harmonic response analysis performed in ANSYS in order to determine the similarity.

\subsection{Experimental frequency response analysis}

The amplitude of vibration of the machine structure was approaching towards nanometer level during machining with two flute milling cutter. The FRF plots along $\mathrm{Y}$ and $\mathrm{Z}$ axes have been shown in Fig. 14. It shows that the maximum deformation of the structure was 0.47 micron in $\mathrm{Y}$ direction while cutting the 

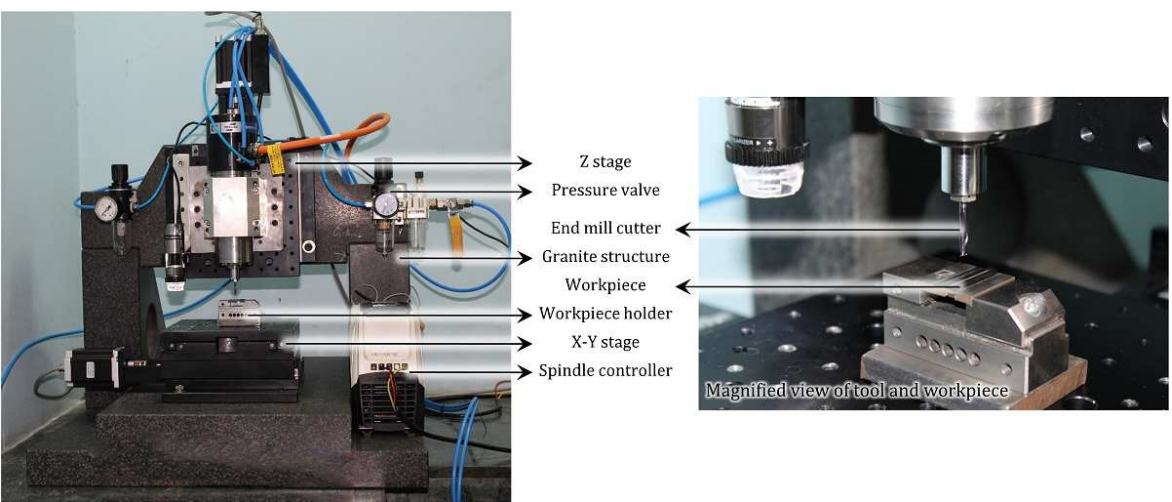

Fig. 13 Assembled high-speed micro-milling machine tool with the proposed machine structure made of natural granite
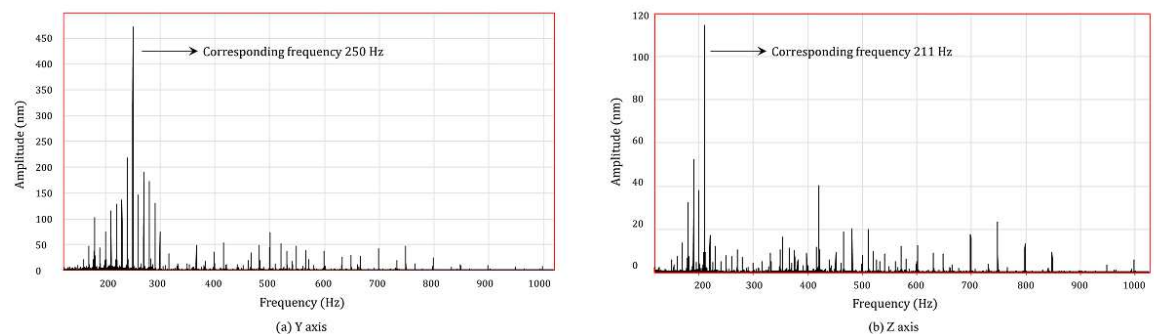

Fig. 14 The results of experimental frequency response analysis of the developed high-speed micro-milling center while machining with two flute milling cutter

same material as previous in mild steel structure. The corresponding frequency at which the maximum deformation occurred was $250 \mathrm{~Hz}$. The maximum deformation of the structure in the $\mathrm{Z}$ direction was 0.112 micron while the machining operation and the corresponding frequency at resonance was $211 \mathrm{~Hz}$. The plot was almost similar to that one found in the harmonic response analysis of that model in ANSYS. Slight variation was due to discontinuous plot in experimental frequency response analysis and also due to the presence of higher order frequency. It was found that the resonance zone occurred in between $190 \mathrm{~Hz}$ and $270 \mathrm{~Hz}$. However amplitude is more dominant at $250 \mathrm{~Hz}$ along $\mathrm{Y}$ axis and $211 \mathrm{~Hz}$ along $\mathrm{Z}$ axis. The amplitude of vibration has been reduced with increase in rotational speed because lower force transmission at higher rotational speed. Hence, it was observed that the deformation has been reduced 12 times as compared to the previous mild steel structure.

The machining operation performed by four flute milling cutter precipitated that maximum deformation along $\mathrm{Y}$ direction was 0.38 micron and corresponding resonant frequency was $250 \mathrm{~Hz}$. However, the maximum deformation along $\mathrm{Z}$ axis was 0.091 micron and corresponding resonant frequency was $211 \mathrm{~Hz}$. The frequency response plots along $\mathrm{Y}$ and $\mathrm{Z}$ axes for this experiment have been depicted in Fig. 15. This experiment has shown good similarity 

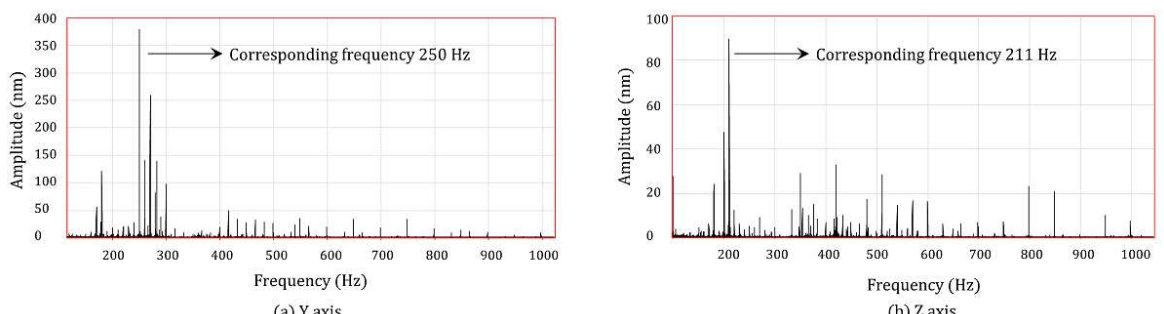

(a) Yaxis

Fig. 15 The results of experimental frequency response analysis of the developed high-speed micro-milling center while machining with four flute milling cutter

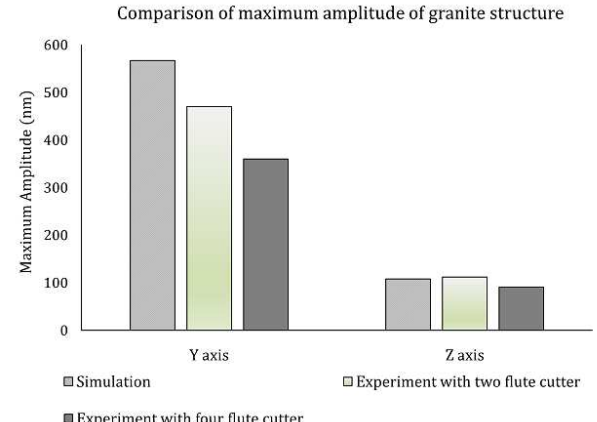

(a)

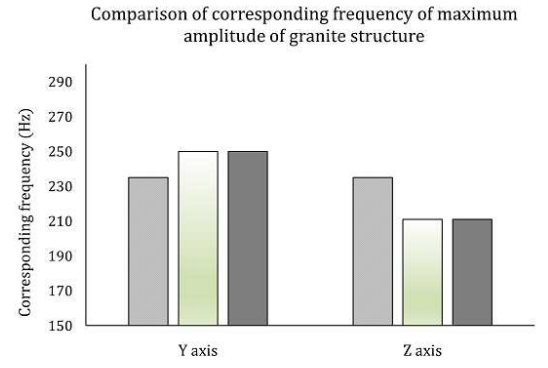

口simulation घexperiment with four flute cutter (b)

Fig. 16 (a) Comparison of maximum amplitude; and (b) comparison corresponding frequencies of the developed micro-milling center, determined in ANSYS harmonic response analysis, experimental frequency response analysis with two flute cutter and experimental frequency response analysis with four flute cutter

with the resonant frequencies achieved in previous experimental result as well as in the result of ANSYS. The plot was almost similar with the plot achieved in simulation. Probable occurrence of second order frequency (higher order) has led to a peak at $422 \mathrm{~Hz}$ along $\mathrm{Z}$ axis. The variation of amplitude was due to the variation of cutting force in both experiments. However, a constant average cutting force was considered in harmonic response analysis in ANSYS. The comparisons of maximum amplitudes and corresponding frequencies determined in both the experiments and the FEM analysis have shown in Fig. 16.

The deformation found was almost negligible, therefore, it can be concluded that the structure is vibration free upto the maximum rotational speed of the working spindle. The amplitude has a tendency to be reduced with operating frequency. Therefore, the machine structure can be operated for ultra-high speed machining as well. The machining vibration has been reduced to great extent using the developed machine structure. During micro-milling operation, an average surface finish of $100 \mathrm{~nm}$ has been achieved on difficult-to-cut materials. The machining was performed upto the maximum rotational speed 


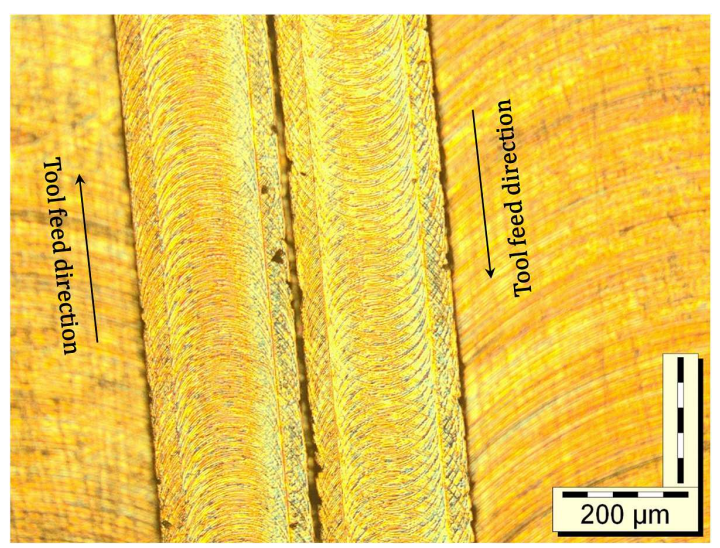

Fig. 17 Tool feed marks on micro grooves of $200 \mu \mathrm{m}$ width and $60 \mu \mathrm{m}$ depth, generated on high strength super alloy Ti6Al4V by high-speed micro-milling

of the spindle without breakage of the cutting tool. Hence the accuracy, precision, surface finish of micro-machining as well as the tool life of the micro cutting tool was maintained for that micro-milling center. Figure 17 depicted the movement of the milling cutter on the workpiece surface during micromilling operation. It can be seen that the tool movement was uniform along the infeed direction and any transverse movement due to vibration was not found.

\section{Conclusions}

In this study, a design approach of vibration free machine structure has been presented for a high-speed micro-milling machine tool. This design methodology has incorporated the modeling and assembly of the machine structure including material selection. Subsequently, FEM analyses i.e. static structural analysis, modal analysis and harmonic response analysis have been performed to evaluate the static and dynamic performances of the assembled machine structure. Based on the results of FEM analyses, the best model have been selected as vibration free and proposed for manufacturing. Eventually, experimental frequency response analyses have been performed during machining to check the similarity with FEM results. The experimental results have shown well similarities with the FEM results in terms of resonant frequencies, amplitude of vibration and natural frequencies. During high-speed micro-milling operation, an average surface roughness of $100 \mathrm{~nm}$ with uniform tool feed marks have been observed on the machined surface of difficult-to-cut materials. Based on this study, the following conclusions can be made:

1. The design approach has been focused on developing a rigid vibration free machine structure. The developed machine structure has provided good static, dynamic stiffness and damping performance to the high-speed micromilling machine tool. The amplitude of vibration has been reduced by 12 
times with this structure as compared to previous mild steel structure. Therefore, the machine tool vibration has been reduced significantly utilizing this machine structure. The design approach is appropriate for vibration isolation without utilizing any vibration absorber.

2. Natural granite has shown better stiffness, rigidity and damping performance as compared to cast iron. Therefore, the machine structure made of natural granite has shown better performance than structure made of cast iron to reduce structural vibration.

3. The amplitude of vibration has been reduced with increasing the cutting speed (rotational speed). This is due to lower force transmission at higher cutting speed. Hence, the developed machine structure can be utilized for ultra-high speed machining as well.

4. The amplitude of vibration in the machine tool has been reduced during machining with a four flute milling cutter as compared to two flute milling cutter under similar machining condition. Machining with four flute milling cutter precipitated lower chip load resulted in lower cutting force. Therefore, force transmission to the machine tool has been reduced utilizing four flute milling cutter. Thus machine tool vibration has been reduced.

5. The design of the machine structure has been optimized to minimize the vibration. The thickness, height and width of all components of the structure have been determined considering vibration point of view; and to reduce cantilever effect, and to improve structural stiffness. The next step is to develop an ultra-high speed micro-milling center incorporating this developed machine structure which can be a part of the future research.

Acknowledgements This research work has been financially supported by Department of Science and Technology (DST), India under project number DST(SERB)/533/201718/Mechanical Engineering. The design of the vibration free machine structure has been applied for Indian Patent with application no. 201931049978, which has been published on 24th July, 2020.

\section{Declarations}

Funding

Not applicable

Conflict of interest

The authors declare no conflict of interest.

Availability of data and material

All data are accurate and generated from official sources. 
Code availability

Not applicable

\section{Authors' contributions}

Vivek Bajpai has planned and defined the methodology of the research work and arranged necessary funding. Arnab Das has performed the simulations. Shashank Shukla has participated in the purchasing work and performed the assembly of the machine tool. Arnab Das, Mohan Kumar and Chitransh Singh have performed the experiments and analysis. Madan Lal Chandravanshi have provided the necessary instruments for experiments and prepared experimental planning. Arnab Das and Vivek bajpai have participated in paper writing and necessary revisions of it. All authors read and approved the final manuscript.

\section{References}

1. Huo D, Cheng K, Wardle F (2010) Design of a five-axis ultra-precision micro-milling machine - ultramill. part 1: holistic design approach, design considerations and specifications. Int J Adv Manuf Technol 47(9-12):867-877

2. Filiz S, Conley CM, Wasserman MB, Ozdoganlar OB (2007) An experimental investigation of micro-machinability of copper 101 using tungsten carbide micro-endmills. Int J Mach Tools Manuf 47(7-8):1088-1100

3. Friedrich CR, Vasile MJ (1996) Development of the micromilling process for high-aspectratio microstructures. J Microelectromech Syst 5(1):33-38

4. Wang Y, Zou B, Wang J, Wu Y, Huang C (2020) Effect of the progressive tool wear on surface topography and chip formation in micro-milling of ti-6al-4v using ti (c7n3)based cermet micro-mill. Tribol Int 141:105900

5. Abidin ZZ, Mativenga PT, Harrison G (2020) Chilled air system and size effect in micromilling of nickel- titanium shape memory alloys. Int J Precis Eng Manuf-Green Technol $7(2): 283-297$

6. Huo D, Lin C, Choong ZJ, Pancholi K, Degenaar P (2015) Surface and subsurface characterisation in micro-milling of monocrystalline silicon. Int J Adv Manuf Technol 81(5-8):1319-1331

7. Jun MB, Liu X, DeVor RE, Kapoor SG (2006) Investigation of the dynamics of microend milling - part i: model development. J Manuf Sci Eng. Trans ASME 128(4):893-900

8. Zaeh M, Siedl D (2007) A new method for simulation of machining performance by integrating finite element and multi-body simulation for machine tools. CIRP Ann 56(1):383-386

9. Huo D, Cheng K, Wardle F (2010) Design of a five-axis ultraprecision micro-milling machine-ultramill. part 2: integrated dynamic modelling, design optimization and analysis. Int J Adv Manuf Technol 47:879-890

10. Suh J, Lee DG, Kegg R (2002) Composite machine tool structures for high speed milling machines. CIRP Ann 51(1):285-288

11. Quintana G, Ciurana J (2011) Chatter in machining processes: A review. Int J Mach Tools Manuf 51(5):363-376

12. Clancy BE, Shin YC (2002) A comprehensive chatter prediction model for face turning operation including tool wear effect. Int J Mach Tools Manuf 42(9):1035-1044

13. Chen W, Luo X, Su H, Wardle F (2016) An integrated system for ultra-precision machine tool design in conceptual and fundamental design stage. Int J Adv Manuf Technol 84(58):1177-1183 
14. Bryan JB (1979) Design and construction of an ultraprecision 84 inch diamond turning machine. Precis Eng 1(1):13-17

15. Luo X, Cheng K, Webb D, Wardle F (2005) Design of ultraprecision machine tools with applications to manufacture of miniature and micro components. J Mater Process Technol 167(2-3):515-528

16. Huo D, Cheng K, Wardle F (2010) A holistic integrated dynamic design and modelling approach applied to the development of ultraprecision micro-milling machines. Int J Mach Tools Manuf 50(4):335-343

17. Park HW, Park YB, Liang SY (2011) Multi-procedure design optimization and analysis of mesoscale machine tools. Int J Adv Manuf Technol 56(1-4):1-12

18. Liang Y, Chen W, Bai Q, Sun Y, Chen G, Zhang Q, Sun Y (2013) Design and dynamic optimization of an ultraprecision diamond flycutting machine tool for large kdp crystal machining. Int J Adv Manuf Technol 69(1-4):237-244

19. Yang X, Zheng J, Xu J, Li W, Wang Y, Fan M (2020) Structural design and isolation characteristic analysis of new quasi-zero-stiffness. J Vib Eng Technol 8(1):47-58

20. Zhang Z, Zhang YW, Ding H (2020) Vibration control combining nonlinear isolation and nonlinear absorption. Nonlinear Dyn 100:2121-2139

21. Semm T, Nierlich MB, Zaeh MF (2019) Substructure coupling of a machine tool in arbitrary axis positions considering local linear damping models. J Manuf Sci Eng. Trans ASME 141(7):071014

22. Zhang X, Yin Z, Gao J, Liu J, Gao RX, Cao H, Chen X (2019) Discrete time-delay optimal control method for experimental active chatter suppression and its closed-loop stability analysis. J Manuf Sci Eng. Trans ASME 141(5):051003

23. Orra K, Choudhury SK (2020) Stability analysis in machining process by using adaptive closed-loop feedback control system in turning process. J Vib Control 0(0):1-13

24. Yuksel E, Erturk AS, Budak E (2020) A hybrid contact implementation framework for finite element analysis and topology optimization of machine tools. J Manuf Sci Eng. Trans ASME 142(8):081001

25. Mohammadi Y, Ahmadi K (2020) Single degree-of-freedom modeling of the nonlinear vibration response of a machining robot. J Manuf Sci Eng. Trans ASME 143(5):051003

26. Raze G, Kerschen G (2020) Multimodal vibration damping of nonlinear structures using multiple nonlinear absorbers. Int J Nonlin Mech 119:103308

27. Saber H, Samani FS, Pellicano F (2020) Nonlinear vibration absorbers applied on footbridges. Meccanica pp. 1-18

28. Do Suh J, et al. (2008) Design and manufacture of hybrid polymer concrete bed for high-speed cnc milling machine. Int J Mech Mater Des 4(2):113-121

29. Huo D, Cheng K (2008) A dynamics-driven approach to the design of precision machine tools for micro-manufacturing and its implementation perspectives. Proc Inst Mech Eng B J Eng Manuf 222(1):1-13

30. Rao S (1997) Metal cutting machine tool design — a review. J Manuf Sci Eng. Trans ASME 119(4B):713-716

31. Möhring HC, Brecher C, Abele E, Fleischer J, Bleicher F (2015) Materials in machine tool structures. CIRP Ann 64(2):725-748

32. Chen TC, Chen YJ, Hung MH, Hung JP (2016) Design analysis of machine tool structure with artificial granite material. Adv Mech Eng 8(7):1-14

33. de Bruin W, Meijer J (1980) Analysis of flatness measurement and form stability of a granite surface plate. CIRP Ann: Manuf Technol 29(16):385-390 


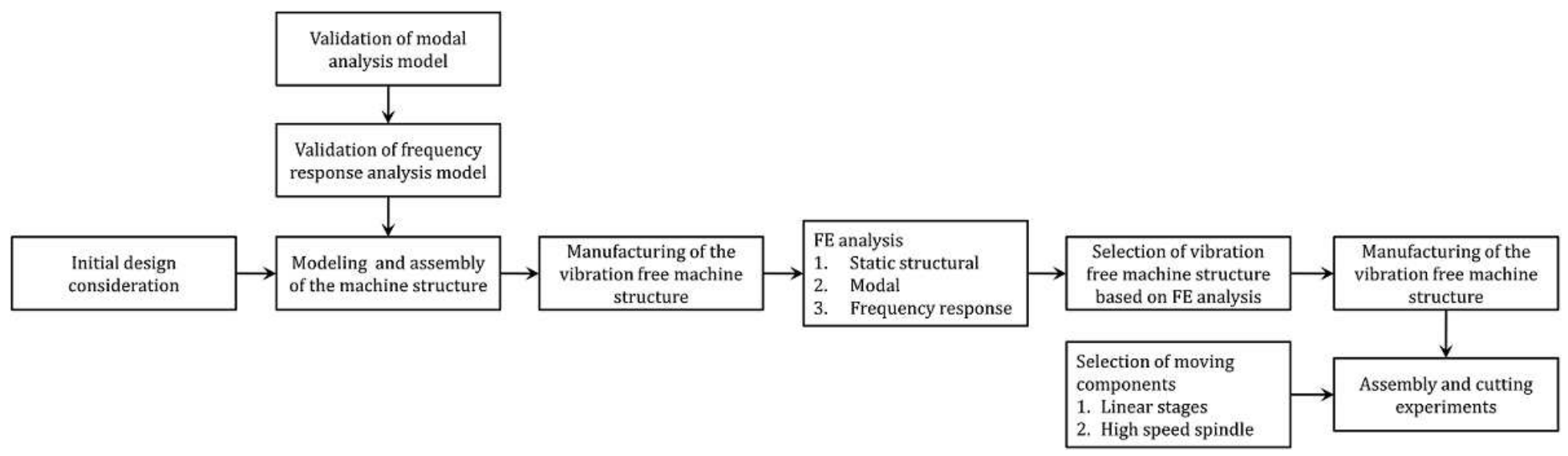

\section{Figure 1}

Flow chart of the design methodology

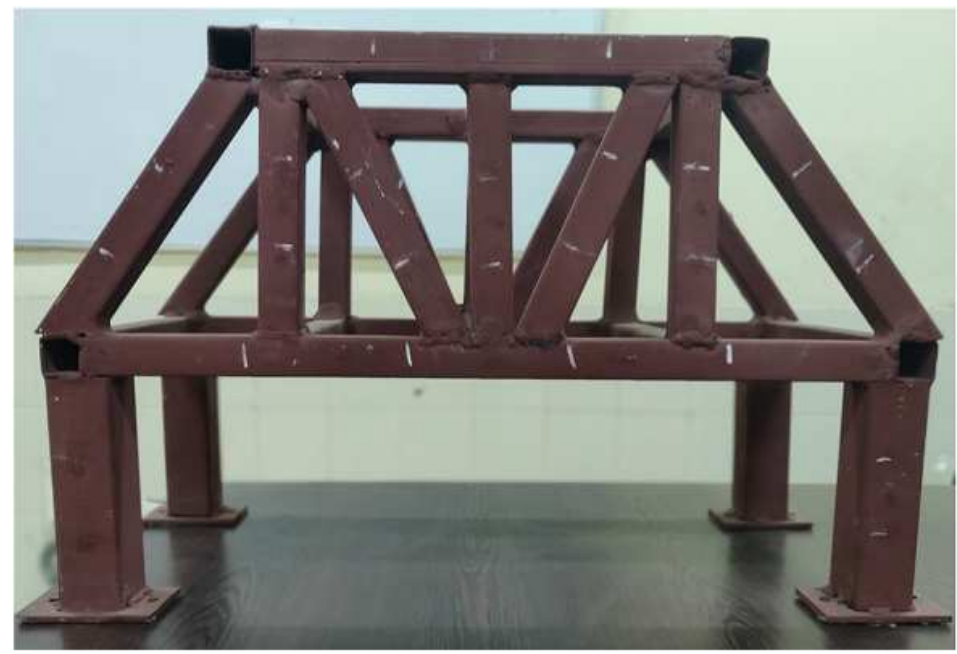

(a)

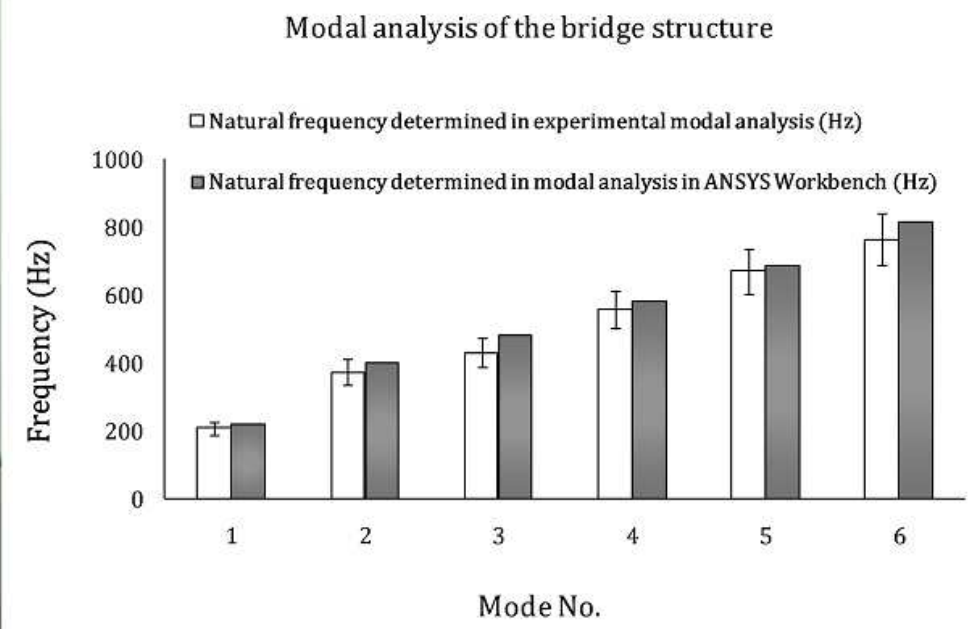

(b)

\section{Figure 2}

(a) The bridge structure used for validation of modal analysis model in ANSYS workbench, (b) the comparison of natural frequencies of the bridge structure found in ANSYS modal analysis and experimental modal analysis 


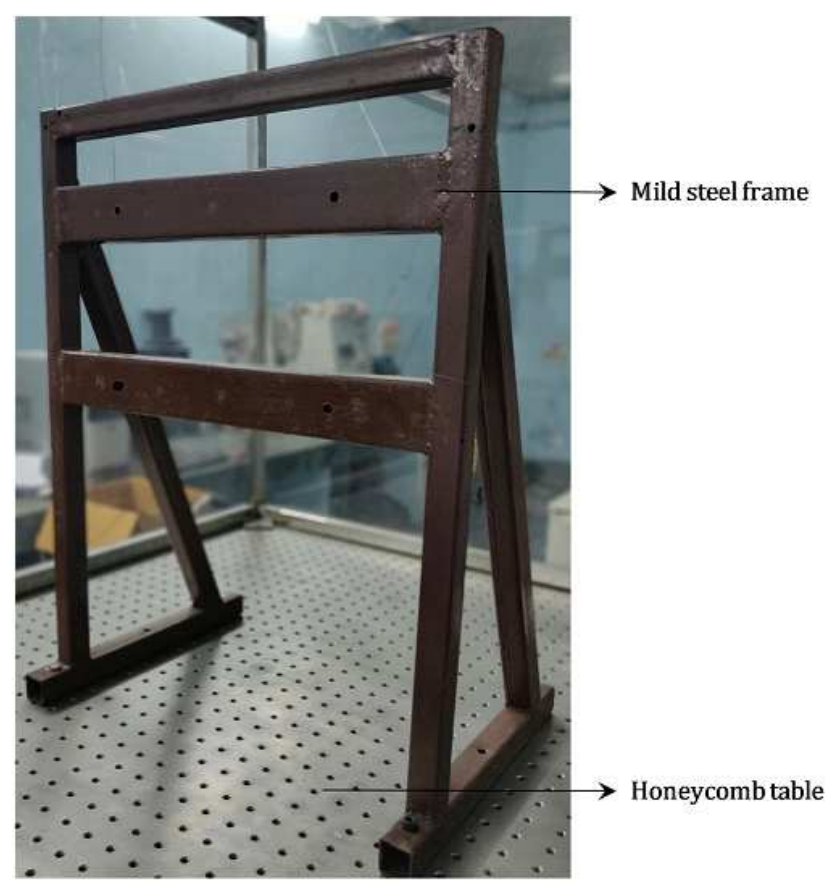

(a)

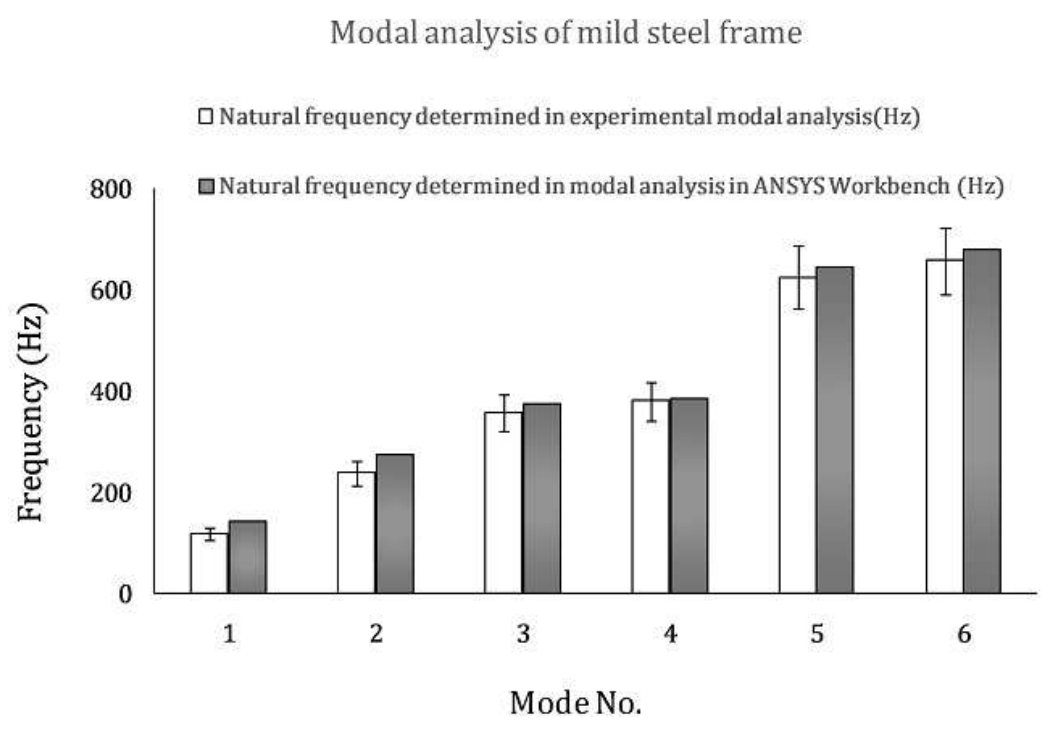

(b)

\section{Figure 3}

(a) The mild steel frame for the micro-milling set up, (b) the comparison of natural frequencies of the mild steel frame determined in ANSYS modal analysis and experiments

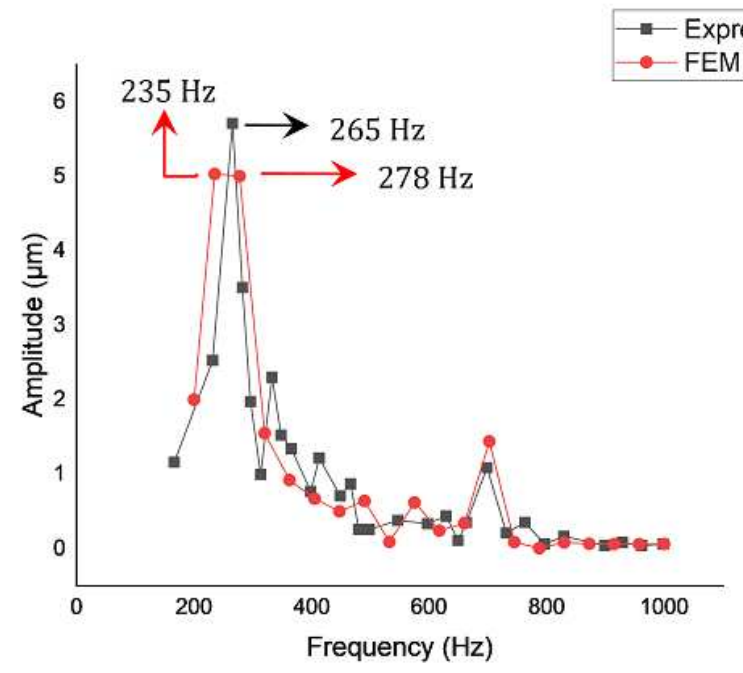

(a) Y axis

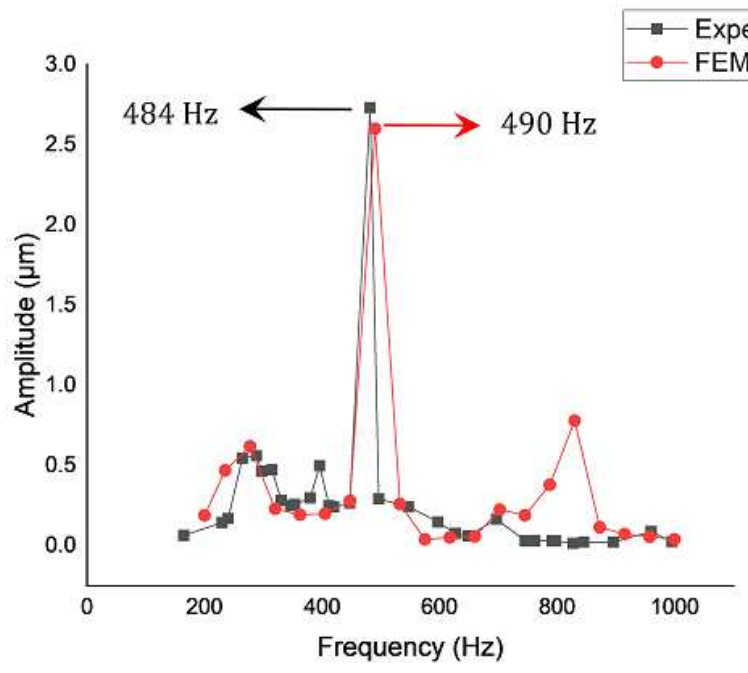

(b) Z axis

\section{Figure 4}

Comparison of the results of frequency response analysis on the mild steel frame determined in experiments and FEM analysis 
Comparison of Natural frequency using cast iron and natural granite

$\square$ Natural frequency of the structure using material cast iron $(\mathrm{Hz})$

$\square$ Natural frequency of the structure using material natural granite $(\mathrm{Hz})$

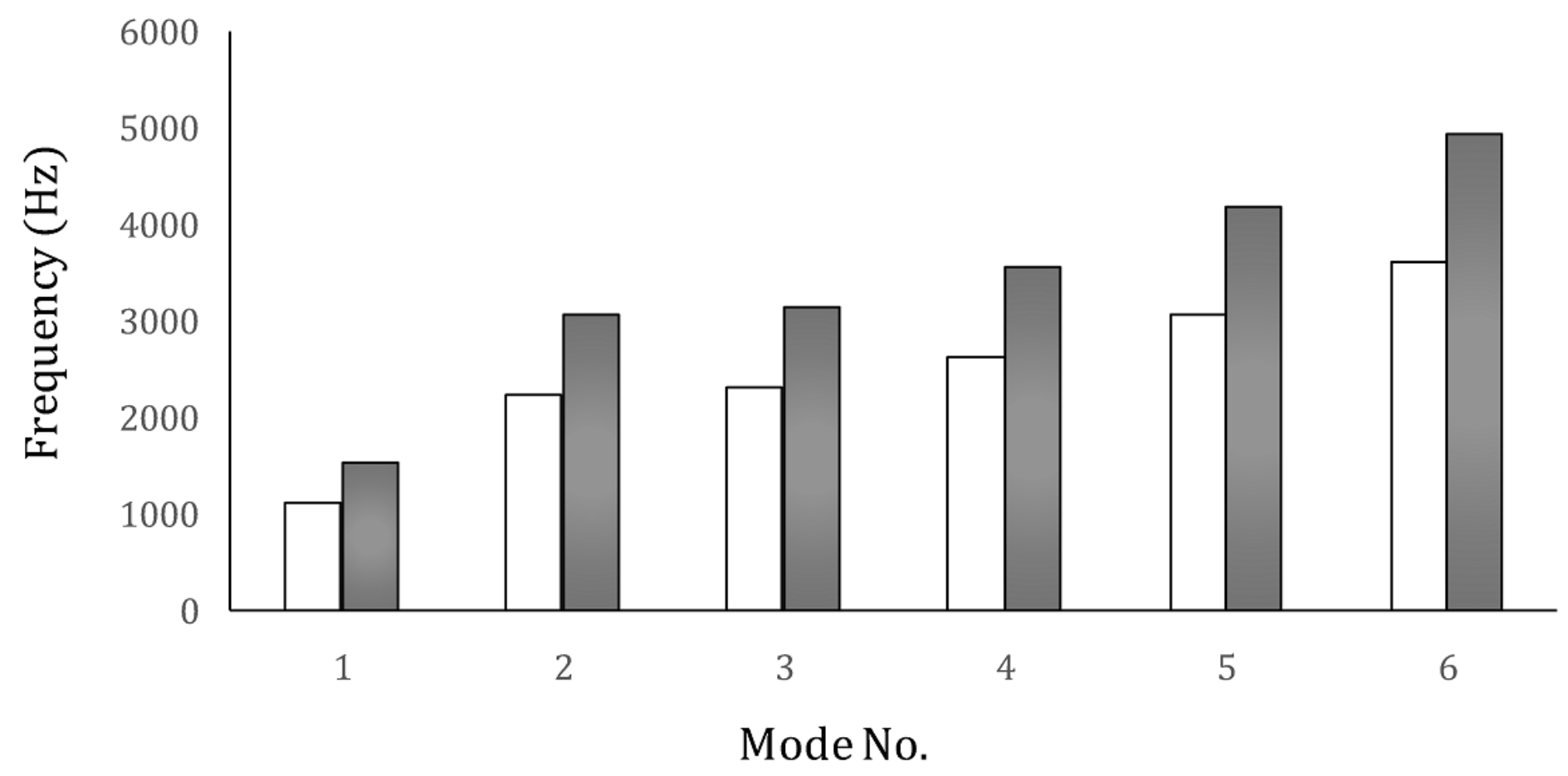

Figure 5

The comparison of natural frequencies of the proposed machine structure using cast iron and natural granite 


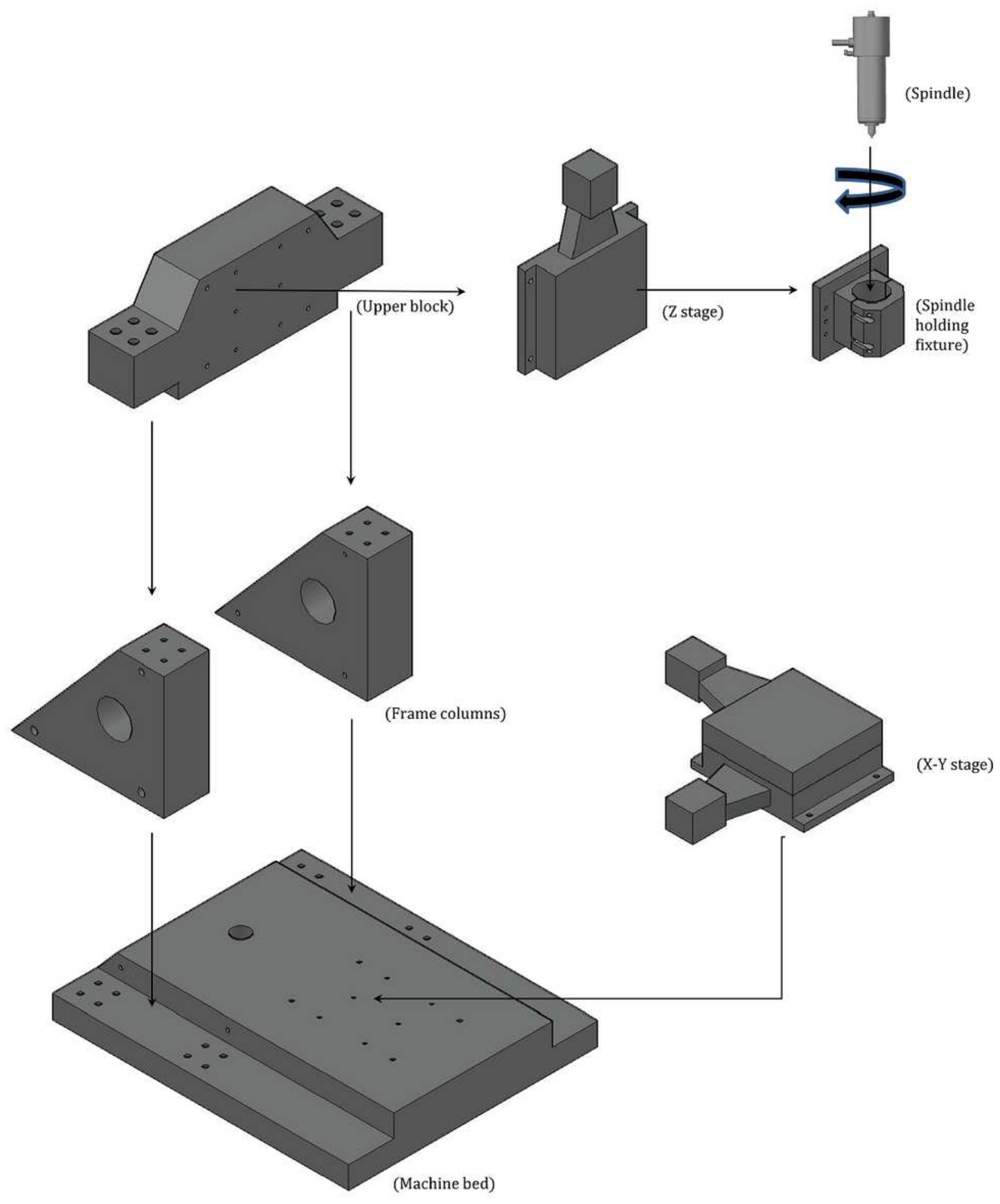

Figure 6

The components of the vibration free high-speed micro-milling center prepared in AutoCAD 


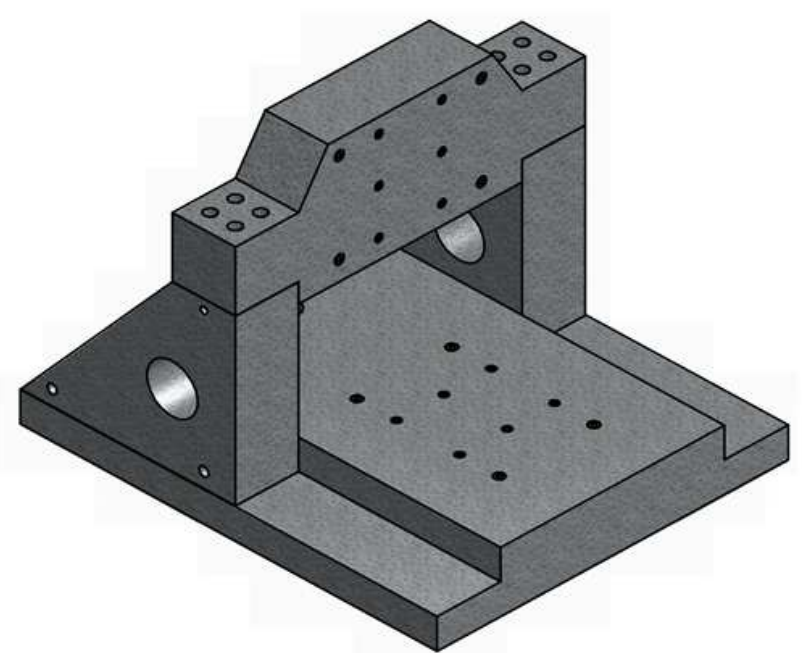

(a) Unassembled machine structure

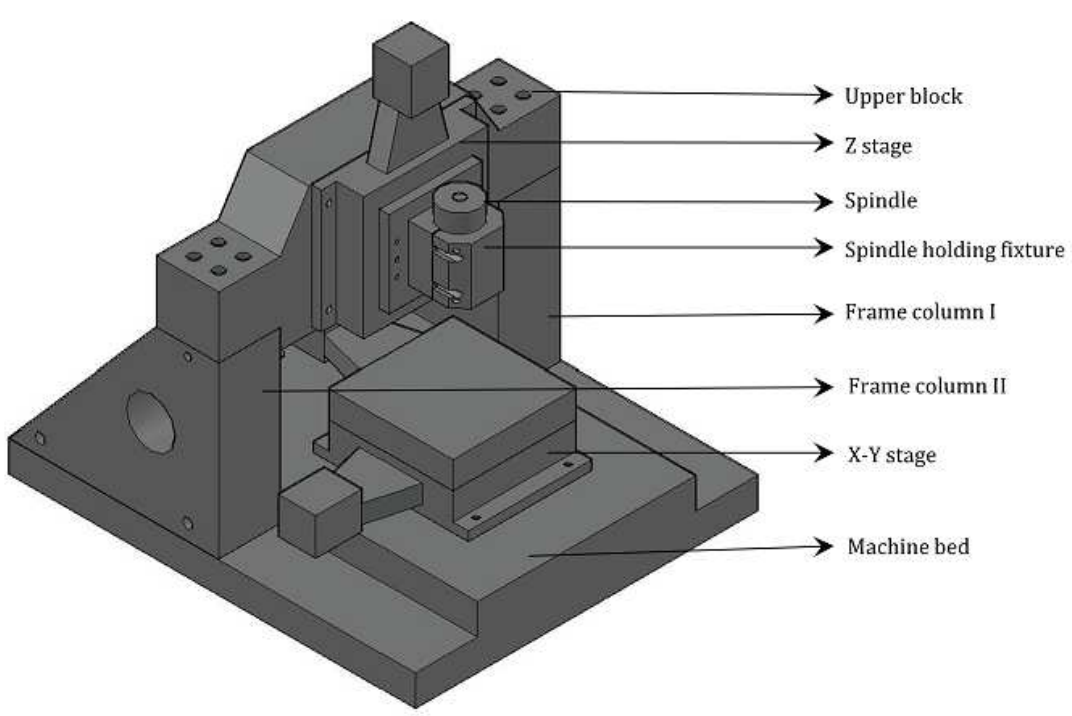

(b) Assembled machine structure

\section{Figure 7}

CAD model of the vibration free machine structure

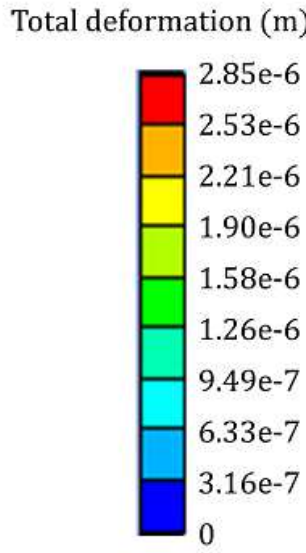

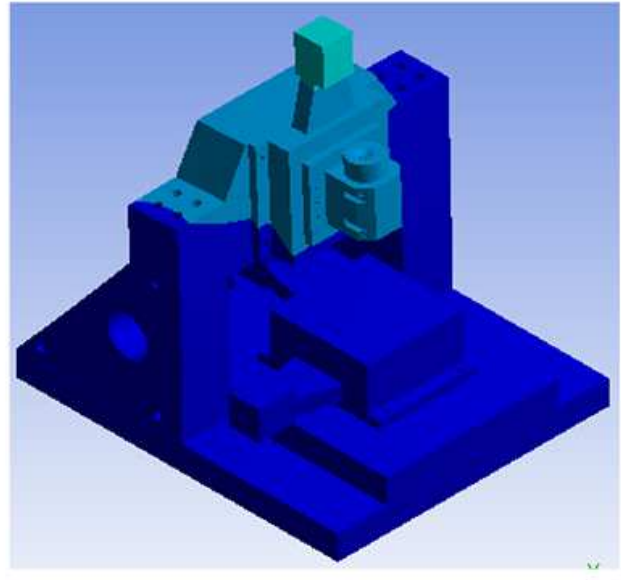

(a)

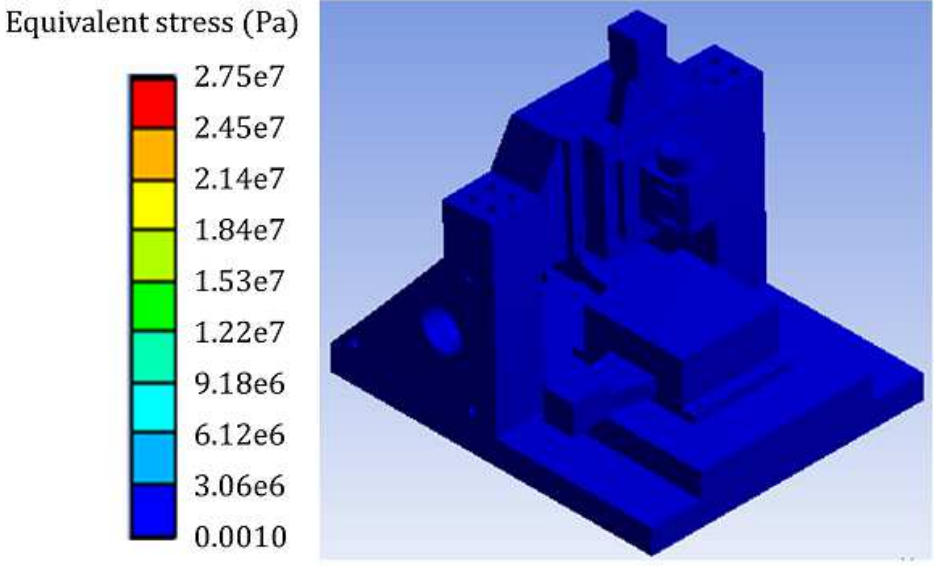

(b)

\section{Figure 8}

The results of static structural analysis of the proposed model determined in ANSYS workbench. (a) Total deformation, and (b) Equivalent stress 


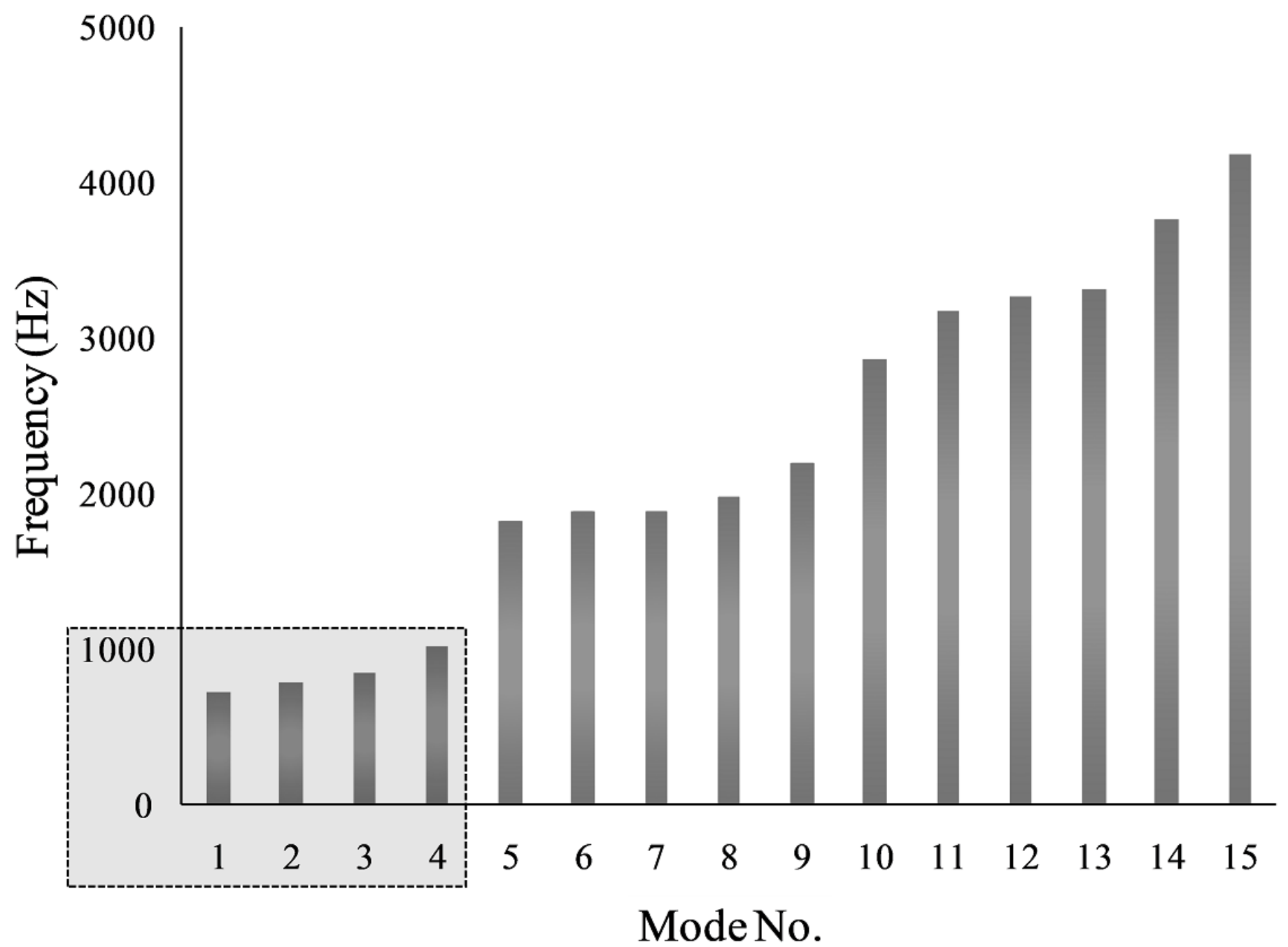

Figure 9

Plots of rst 15 natural frequencies of the proposed assembled machine structure determined in ANSYS modal analysis

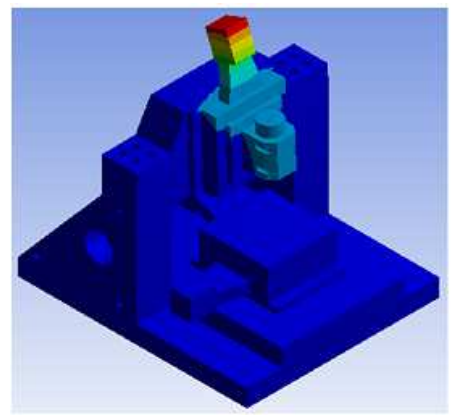

(a) $1^{\text {st }}$ Mode shape

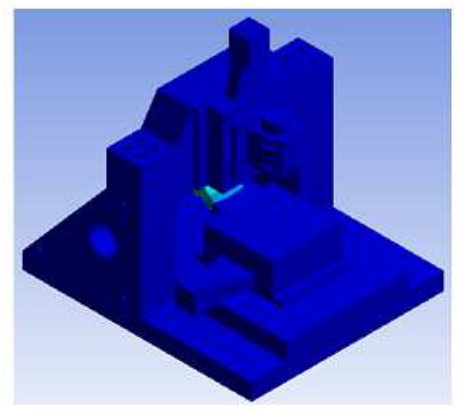

(b) $2^{\text {nd }}$ Mode shape

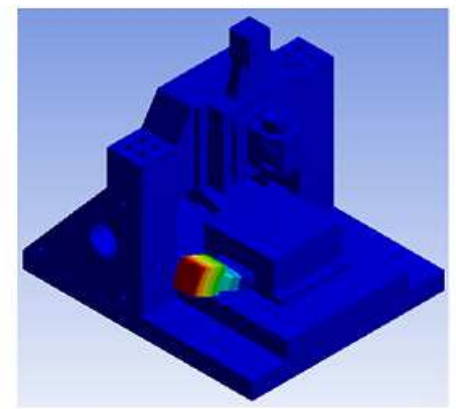

(c) $3^{\text {rd }}$ Mode shape

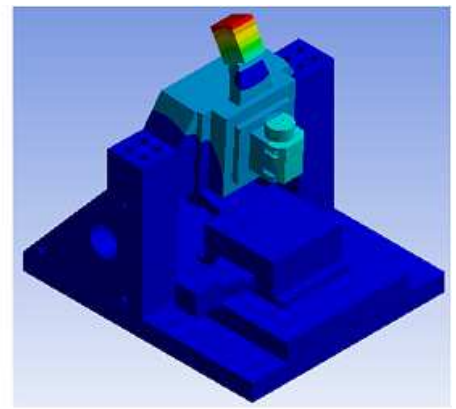

(d) $4^{\text {th }}$ Mode shape

Figure 10

First four mode shapes of the assembled machine structure, determined in ANSYS modal analysis 


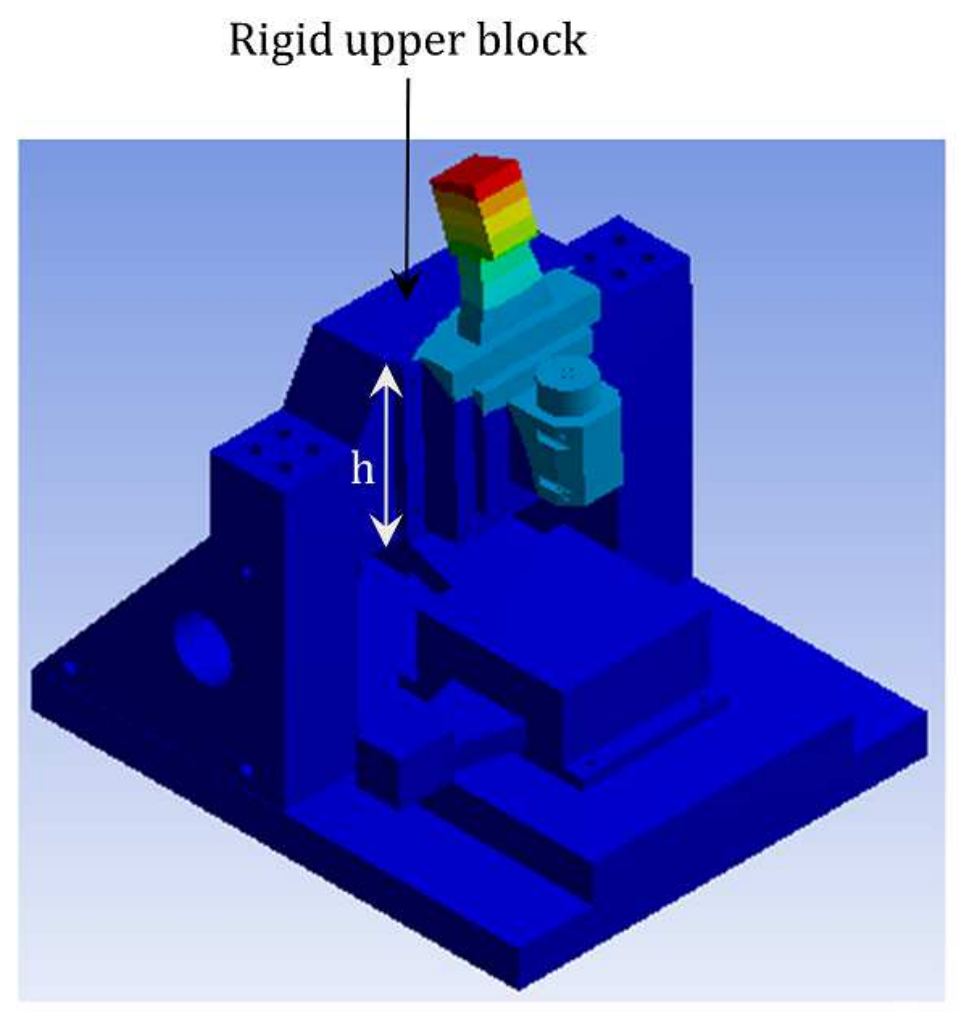

(a) $\mathrm{h}=207.5 \mathrm{~mm}$

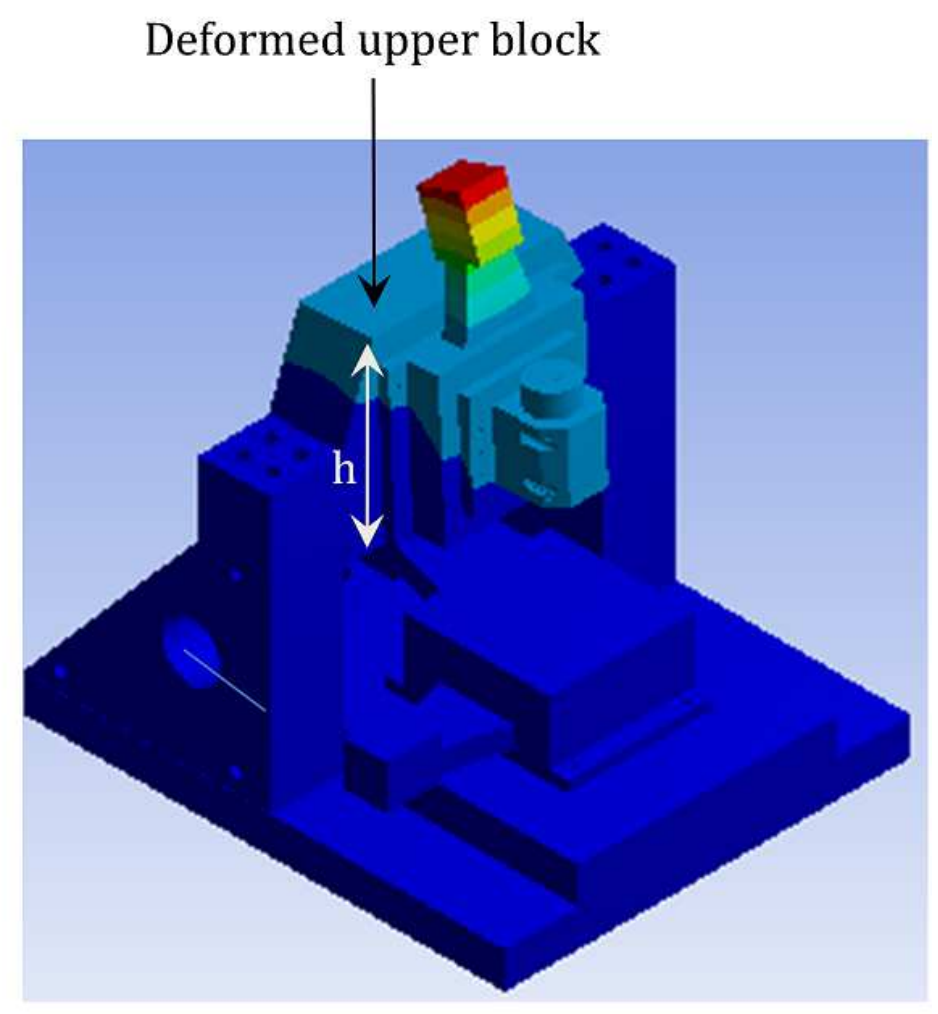

(b) $\mathrm{h}=250 \mathrm{~mm}$

\section{Figure 11}

First mode shapes of the assembled machine structure with di囚erent heights of the upper block

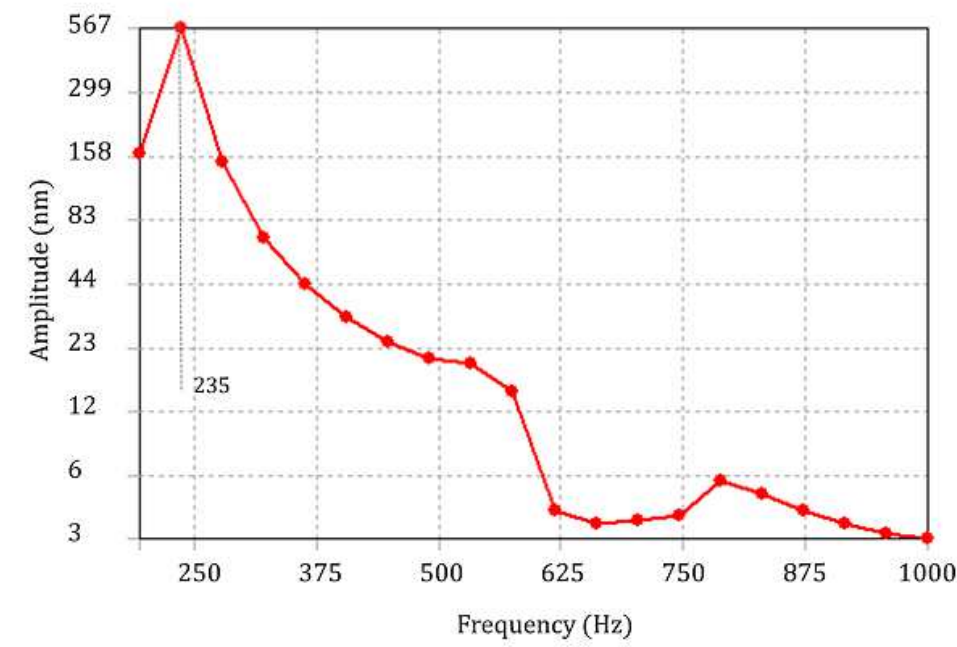

(a) Y axis

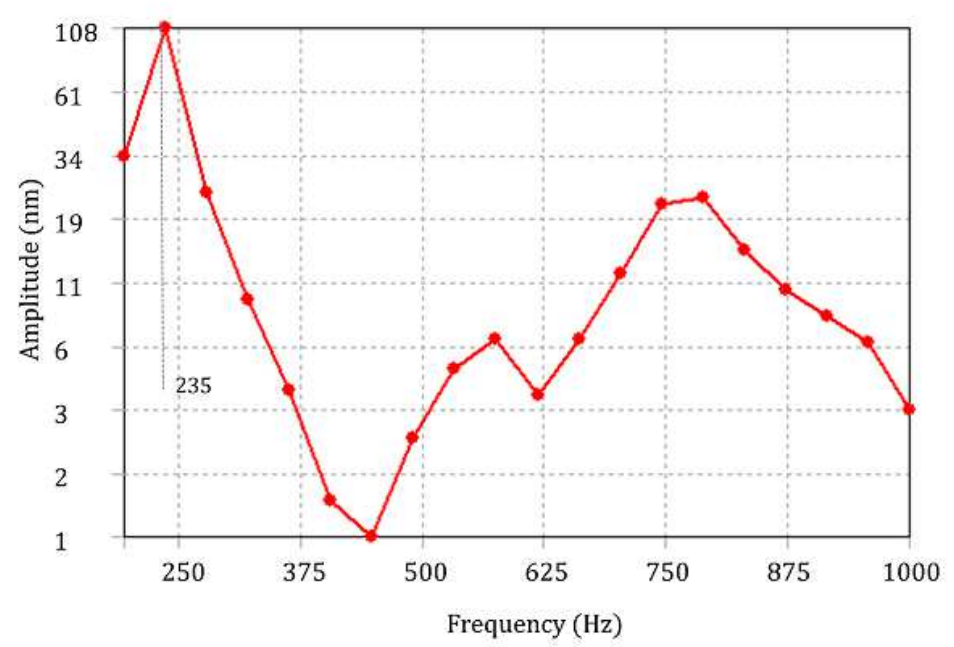

(b) $\mathrm{Z}$ axis

Figure 12

Plots of harmonic response analysis of the assembled machine tool model determined in ANSYS 


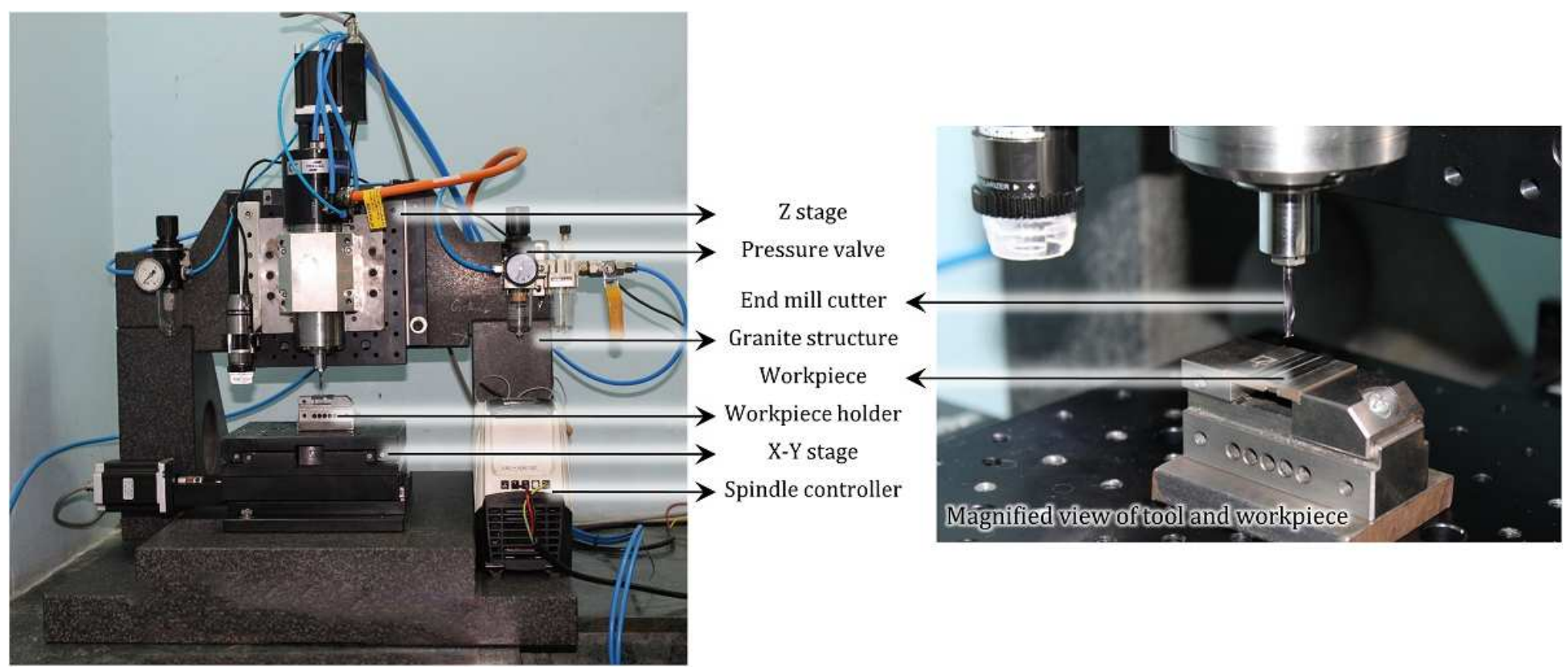

Figure 13

Assembled high-speed micro-milling machine tool with the proposed machine structure made of natural granite

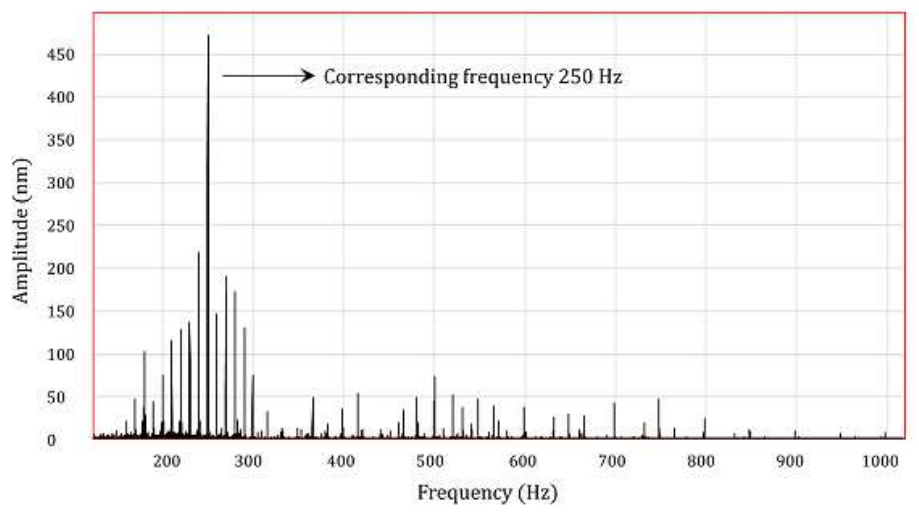

(a) Y axis

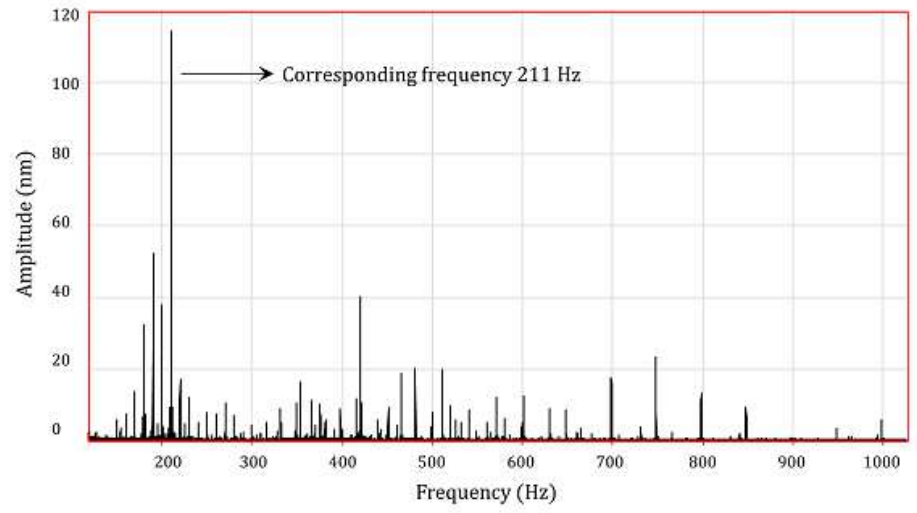

(b) $\mathrm{Z}$ axis

\section{Figure 14}

The results of experimental frequency response analysis of the developed high-speed micro-milling center while machining with two ute milling cutter 


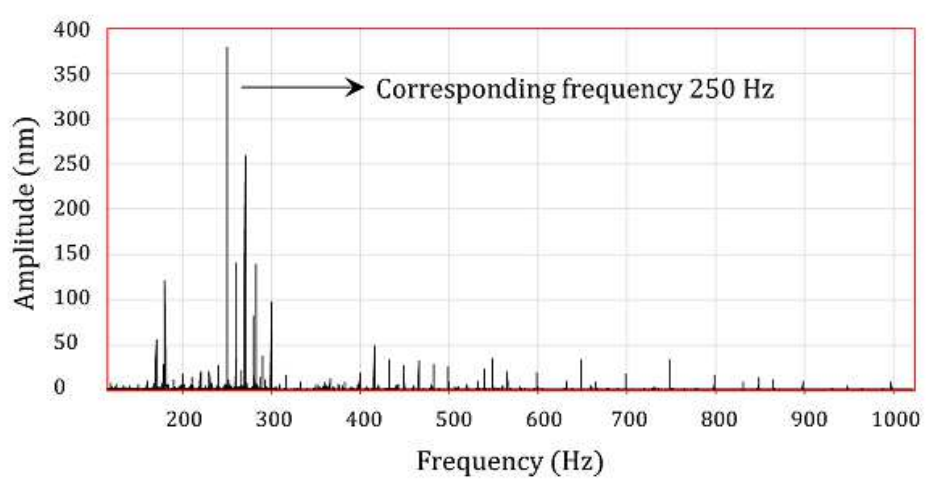

(a) Y axis

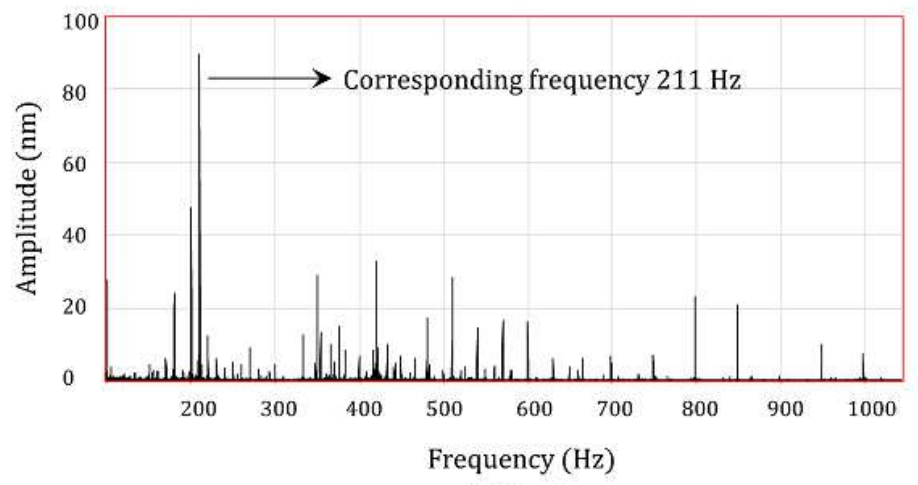

(b) $\mathrm{Z}$ axis

\section{Figure 15}

The results of experimental frequency response analysis of the developed high-speed micro-milling center while machining with four ute milling cutter

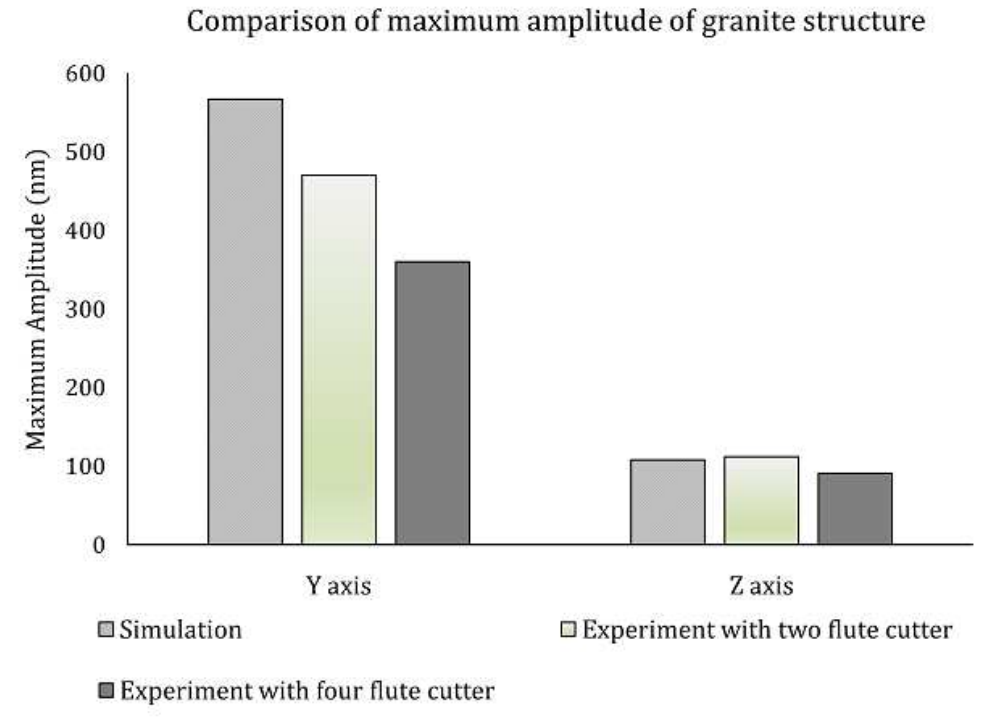

(a)
Comparison of corresponding frequency of maximum amplitude of granite structure

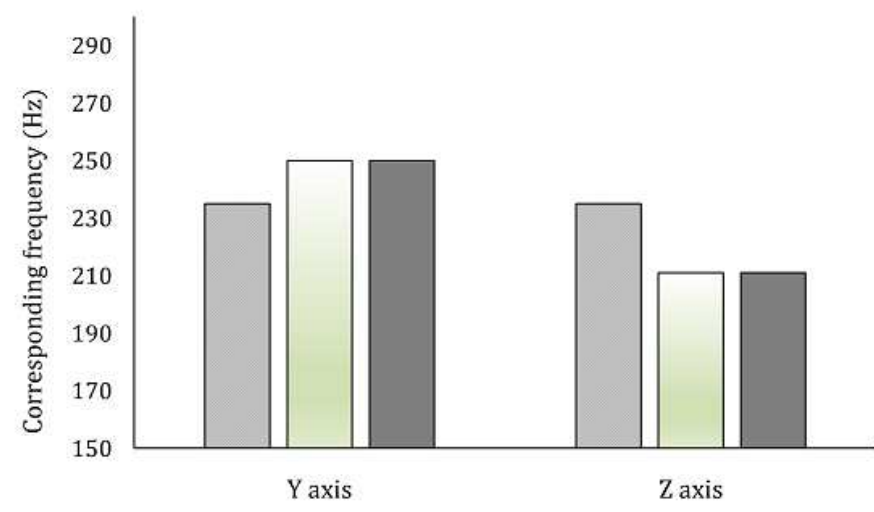

口simulation $\square$ experiment with two flute cutter $\square$ experiment with four flute cutter

(b)

\section{Figure 16}

(a) Comparison of maximum amplitude; and (b) comparison corresponding frequencies of the developed micro-milling center, determined in ANSYS harmonic response analysis, experimental frequency response analysis with two ute cutter and experimental frequency response analysis with four ute cutter 


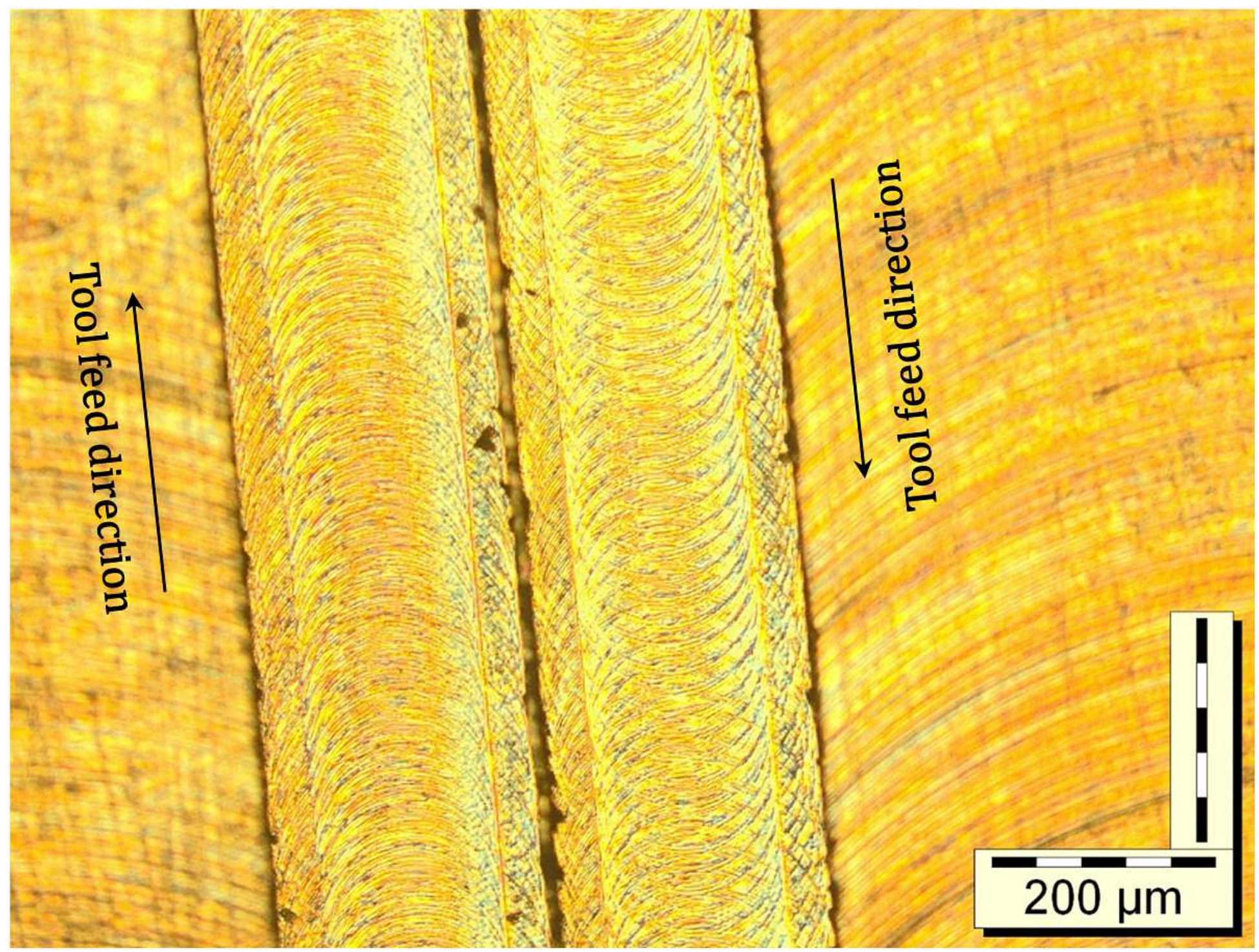

Figure 17

Tool feed marks on micro grooves of $200 \mu \mathrm{m}$ width and $60 \mu \mathrm{m}$ depth, generated on high strength super alloy Ti6Al4V by high-speed micro-milling 